\title{
Hacia una tipología de la piedra de marés de Mallorca. Concepto, caracterización y estratigrafía
}

\author{
G. Mas Gornals \\ Societat Geocientífica de les Illes Balears (GEOilles). Carrer Estrella de Mar, 4, 5B, 07638 Colònia de Sant Jordi (Mallorca - Illes Balears) \\ masgornals@gmail.com
}

\section{RESUMEN}

Se definen el concepto y naturaleza de la piedra calcarenita denominada marés de la isla de Mallorca, a partir de sus características intrínsecas y de uso. Se realiza una clasificación y caracterización tipológica a partir de la cronoestratigrafía y contexto geológico de esta piedra utilizada como material de construcción. Se proporcionan datos históricos y etnológicos sobre su producción y aplicaciones. El marés de Mallorca, junto con las canteras donde se extrae, además de constituir un valioso patrimonio histórico-etnológico-cultural, constituyen también un importante patrimonio geológico-natural que registra y nos permite seguir la evolución y la historia geológica de la isla de Mallorca a través de los últimos 15 millones de años, desde el Mioceno medio (Langhiense-Serravalliense) hasta el Pleistoceno superior.

Palabras clave: calcarenita, estratigrafía, marés, Mallorca, patrimonio geológico, piedra natural.

\section{Towards a typology of the mares sandstone of Mallorca. Concept, characterization and stratigraphy}

\begin{abstract}
The mares calcarenite stone of Mallorca, together with the quarries where it is extracted, is both a valuable ethnic-cultural heritage and an important natural-geological heritage which records and allows us to study the evolution and geological history of the island of Mallorca during the last $15 \mathrm{Ma}$, from the middle Miocene (Langhian-Serravallian) to the upper Pleistocene. In this paper, the concept and nature of the mares sandstone is defined by its intrinsic characteristics and use. First a typological classification is made from the chronostratigraphy and geological context of this stone which has been used as building material. We also provide historical and ethnological data concerning its production and applications.
\end{abstract}

Keywords: calcarenite, geological heritage, Mallorca; mares, natural stone, stratigraphy.

\section{ABRIDGED ENGLISH VERSION}

\section{Introduction}

The mares sandstone has traditionally been the most representative and characteristic building stone on the island of Mallorca, used practically exclusively as construction material for centuries, since the abandonment of stone-and-mortar walls, until its progressive disuse with the appearance of the re-enforced concrete, which finally eclipsed its use. Such emblematic buildings for the island, as Bellver Castle, the Cathedral, La Lonja or the old city walls of Palma, bear witness to this. In Mallorca, the mares sandstone is quarried in the open air or in subterranean galleries.

Vernacular architecture has always used the most accessible appropriate materials, and in the case of the mares sandstone, its abundance, sufficient softness, which facilitates its extraction, together with sufficient hardness to confer solidity and durability in constructions, converge.

The lack of specific scientific and geological data published about the different types of mares in Mallorca, added to the recent resurgence of technical, applied and landscape interest in this stone, have made a revision of its definition, characterization and classification necessary. 
Mas Gornals, G., 2017. Hacia una tipología de la piedra de marés de Mallorca. Concepto... Boletín Geológico y Minero, 128 (2): $301-328$

In this paper the concept and nature of Mallorcan mares sandstone is defined and a typological classification is made from the geological and chronostratigraphic context.

\section{Concept}

The main differential features that characterize Mallorcan mares are:

1. It is a calcarenite. It is a sedimentary rock of a calcareous detrital nature, more or less consolidated, composed of more than $50 \%$ of calcareous elements (bioclasts, oolites, lithoclasts, etc.) pertaining to the sand fraction, with a grain size of between 2 and 1/16 mm, agglutinated by cement.

2. Easy to work. It is characterized by its ease of extraction, cutting and adaptability to the shapes necessary for different uses.

3. Used as a construction material. Its intrinsic characteristics such as ease of cutting allow suitable pieces to be extracted, which gives place to diverse varieties and sizes appreciated for different uses.

4. It is an abundant natural stone in Mallorca and the rest of the Balearic Islands. Its large underground concentration and availability explains its systematic use in construction in these islands.

Taking into account the previous definitions and features, the concept of the sandstone mares is defined as much for (i) its intrinsic material characteristics on the one hand, as for (ii) its possible treatment and uses on the other.

Despite the semantic indication of its name (from the Catalan marès, -esa, adj.: of the sea, relative or pertaining to the sea) it can be formed both from marine sedimentation, that is, in the sea, or from an aeolic origin, that is, from continental sedimentation out of water.

Furthermore, the idea that all mares are from the Quaternary is erroneous, as can be seen in the classification proposed in this paper; some types of Mallorcan mares come from as early as the Middle Miocene (Serravallian-Langhian).

The so-called Santanyí stone is included in this study as, in spite of traditionally being considered a different stone from mares in general, it is also a calcarenite, easy to work and traditionally used in construction.

\section{General characteristics}

The structure, chemical and mineralogical characteristics and physical-mechanical characteristics (apparent density, absorption coefficient, resistance to compression, flexing and impact, porosity, colour, hardness, etc.) are defined.

To summarize, we can define mares sandstone as a material mainly composed of calcium carbonate, of high porosity, in general very soft and of very low resistance to compression compared to other stone used as a construction material. The mares sandstone has different textures, porosity and above all degrees of cementation, which confers a low hardness index, resulting in diverse varieties which are put to different uses. This variability makes this sandstone a difficult material to standardise and/or homologize.

\section{Classification and specific characterization}

Each type of mares sandstone is described by the following items: Concept-basic definition in the territorial area of the island of Mallorca; Traditional name - common traditional and/or commercial names; Stratigraphic Unit - formal denomination of the strata of procedence; Age - age of the rock, indicating, in each case, the method used to determinate it; Distribution - locality of exploitations on the island of Mallorca; Lithology composition, structure and granulometry of the stone; Palaeontology - fossil content; Sedimentary environment - facies (paleo-environment) of formation of the rock; Specific intrinsic features - physical-mechanical characteristics (colour, density, porosity, resistance, hardness, etc.); Representative quarries - main quarries, with municipality indication; Exploitation status - current state of extraction activity; Observations - specific uses, historic-ethnic aspects, varieties, etc.

\section{Typology}

The different varieties of mares in Mallorca have been grouped mainly according to their chronostratigraphic origin, place of procedence and intrinsic characteristics, resulting in a total of 8 types (Fig. 1, Table 1): a) Type $Q$ (Medium-Upper Pleistocene eolianites); b) Type PQ (Plio-Quaternary eolianites); c) Type $P_{2}$ (Pliocene marine 
Mas Gornals, G., 2017. Hacia una tipología de la piedra de marés de Mallorca. Concepto... Boletín Geológico y Minero, 128 (2): $301-328$

biocalcarenites marines); d) Type $P_{1}$ (Pliocene marine calcisiltites); e) Type $M$ (Messinian oolitic limestone); f) Type $T_{2}$ (Upper Tortonian calcisiltites and calcarenites); g) Type $T_{1}$ (Lower Tortonian calcisiltites); and h) Type $S$ (Langhian-Serravallian calcilutites and calcarenites).

\section{Conclusions}

Mallorcan mares together with the quarries where they are extracted, constitute both a valuable historic-ethnic-cultural heritage and an important natural-geological heritage that records the evolution and geological history of the islands during the past $15 \mathrm{Ma}$, from the Middle Miocene (Langhian-Serravallian) to the Upper Pleistocene.

The concept of mares is defined both by its intrinsic characteristics and by its treatment and use. Mares must therefore be defined as a calcarenite, easily worked and used as a construction material, abundant on Mallorca.

Mallorcan mares is a detrital, calcareous, sedimentary rock, more or less consolidated, that includes more than 50 \% calcareous elements (bioclast, lithoclast, etc.), of marine or aeolic origin, pertaining to sand grainsize, with grains between 1 and 1/16 mm, agglutinated by cement. It mainly consists of calcium carbonate, with high porosity, in general very soft and with very low resistance to compression compared to other stones used for construction.

The chronostratigraphy of Mallorcan mares is from the Langhian-Serravalian ( $14 \mathrm{Ma}$ ) to the Upper Pleistocene ( 20,000 years) (Fig. 1).

Eight types of mares (Table 1) have been identified on Mallorca, of which the two most recently formed (types $Q$ and $P Q$ ) are of aeolian origin, whilst the other six are of marine origin. Of these eight types, three $\left(Q, P_{1}\right.$ and $\left.T_{1}\right)$ are no longer exploited or used.

In general, all the types of Mallorcan mares must be considered as a soft or very soft stone. Only type $S$ mares (subtype b), type $M$ (Santanyi Limestone) and some $T_{2}$ types, can be considered as a semi-hard stone.

The variability of intrinsic characteristics (porosity, density, cementation, etc.) and the irregularity of response (absorption, resistance, etc.) make the mares sandstone a difficult material to homologize and standardize.

In the restoration of buildings, when substituting pieces of mares, it is necessary to conserve the original type in order to maintain the characteristics of the genuine heritage.

\section{Introducción}

El marés ha sido tradicionalmente la piedra más representativa y característica de las edificaciones de la isla de Mallorca, utilizada como material de construcción prácticamente exclusivo, durante siglos, desde el abandono de los muros de piedra y mortero hasta llegar a su progresivo desuso con la aparición del hormigón armado, que eclipsó su utilización (Gibert, 1997). Así lo atestiguan edificaciones tan emblemáticas para la isla como el Castillo de Bellver, la Catedral, la Lonja o las antiguas murallas de la ciudad de Palma.

Las arquitecturas vernáculas siempre han usado los materiales apropiados más accesibles, y en el caso del marés convergen su abundante disponibilidad, la suficiente fragilidad, que facilita la extracción y que de forma equilibrada se conjuga con una suficiente dureza necesaria para conferir solidez y durabilidad a las construcciones. En la isla de Mallorca, casas, paredes, vallas, edificios, iglesias... todos parecen compartir aspecto y material de construcción esencial.
La situación geográfica de antiguas explotaciones de esta piedra arenisca ha llegado a determinar, incluso, el trazado de algunas líneas ferroviarias y la ubicación de algunas estaciones de tren, como la antigua estación de los Baños de la Fontsanta en el municipio de Campos, situada cerca de las antiguas canteras de sa Canova, o la estación de Canteras (Son Mesquida) en Felanitx, por su proximidad a las canteras de Son Grau y Son Oliver. Antes, debido a la dificultad de transporte por tierra, la pesada arenisca era principalmente transportada en barcas vía marítima a lo largo de la costa.

Al tratarse de una roca sedimentaria de formación relativamente reciente que prácticamente no ha sufrido los efectos de la deformación tectónica, la piedra de marés se dispone normalmente en estratos horizontales o subhorizontales que, junto con su aparición en grades masas dentro del terreno y subsuelo, facilitan su explotación en forma de cantera. En la isla de Mallorca el marés se extrae en canteras, a cielo abierto o en forma de galerías subterráneas, practicadas dentro de los niveles productivos. La extracción, que antiguamente se hacía de forma manual a golpes 
Mas Gornals, G., 2017. Hacia una tipología de la piedra de marés de Mallorca. Concepto... Boletín Geológico y Minero, 128 (2): $301-328$

de una herramienta específica denominada escoda, actualmente se hace mediante procedimientos mecanizados (disco, moto sierra o cable diamantado).

Los datos aportados por la memoria del Mapa Geològico Nacional (Barnolas, 1991) se reducen a citar la presencia en Mallorca de explotaciones de marés, de grano fino a medio, en las dunas del Holoceno y calcarenitas del Pleistoceno, así como la existencia de algunas canteras para la obtención de sillares para la construcción obtenidos a partir de materiales calizos del Plioceno y Messiniense.

Una guía divulgativa sobre el marés, recientemente publicada (Sánchez-Cuenca, 2010), indica expresamente la dificultad para situar los diferentes tipos en el contexto geológico adecuado, derivada de la actual dispersión de datos fragmentarios publicados.

La falta de datos científicos y geológicos específicos publicados sobre los diferentes tipos de marés existentes en la isla de Mallorca, añadido al reciente resurgimiento del interés técnico-aplicado (Moreno and Muñoz, 1987; Mingarro et al., 1992; Alonso et al., 1996; Garcia-Inyesta and Oliver, 1997; Galvan-Llopis and Ferrer-Graciá, 1997; Pons, 2002; Amengual and Sierra, 2008; Vilafranca-Manguán, 2009, SánchezCuenca, 2010), paisajístico (Florit and Sauleau, 1995; Alomar, 2009; Salvà, 2012, 2013) y patrimonial (Barba, 1999; Mateos et al., 2011) por esta piedra, hacen necesaria una revisión del concepto, así como la caracterización y clasificación de los diferentes tipos de marés (Mas, 2011b).

En el presente trabajo se redefinen el concepto y naturaleza del marés de la isla de Mallorca a la vez que se realiza una clasificación tipológica a partir del contexto geológico y cronoestratigráfico de origen.

\section{Concepto}

Los principales rasgos diferenciales que caracterizan la piedra de marés mallorquina son (Alcover and Moll, 1951-1968; Fullana, 1974; Institut d'Estudis Catalans, 1995; Riba, 1997):

1. Es una calcarenita. Se trata de una roca sedimentaria de naturaleza detrítica caliza, más o menos consolidada, que comprende más del $50 \%$ de elementos calcáreos (bioclastos, oolitos, litoclastos, etc.), transportados o autógenos, pertenecientes a la fracción arena, con granos comprendidos entre 2 y $1 / 16 \mathrm{~mm}$ de grosor, aglutinados por cemento. Algunos tipos de marés, definidos vulgarmente como arcillosos, pueden ser calcisiltíticos con predominio de partículas carbonáticas de tamaño limo y/o arciIla $(<1 / 16 \mathrm{~mm})$.
2. De fácil obrar. Se caracteriza por la facilidad de extracción, corte y adaptación a las formas que nos puedan demandar las necesidades de fábrica de los diferentes espacios constructivos.

3. Usado como material de construcción. Sus características intrínsecas así como la facilidad en el corte permiten extraer las piezas adecuadas para la construcción, lo que da lugar a diversas variedades y tamaños que son apreciadas para usos diversos, desde materiales para levantar elementos estructurales, cierres y techumbres hasta para elaborar acabados y elementos ornamentales.

4. Se trata de una piedra natural abundante en Mallorca y en el resto de las Islas Baleares. Su amplia distribución y disponibilidad en el terreno, explicaría su sistemática utilización como material constructivo en las Islas Baleares.

Teniendo en cuenta las definiciones y rasgos anteriores, el concepto de marés nos vendría definido tanto (i) por las características intrínsecas de estos materiales, como (ii) por el tratamiento y el uso que se puede hacer de ellos.

Independientemente de lo que semánticamente su propio nombre indica (del catalán marès, -esa adj.: del mar, relativo o perteneciente al mar) se puede tratar tanto de un material calcáreo formado en el mar (sedimentación marina) como de una acumulación carbonática de origen eólico, formada fuera del agua (sedimentación continental). En este último caso se trata de una eolianita o arenisca calcárea formada por la consolidación del sedimento acumulado por el viento, especialmente en forma de dunas "fósiles" formadas por arenas de grano fino a grueso constituidas por restos de foraminíferos, algas, conchas, etc.

También debe abandonarse la idea errónea de que todo el marés es de edad cuaternaria (Fullana, 1974), ya que, como podremos ver más adelante en la clasificación que se propone en este trabajo, algunos tipos de calcarenitas mallorquinas pueden tener edades de hasta el Mioceno medio (Serravalliense-Langhiense).

Se incluye en este estudio la denominada piedra de Santanyí, ya que, a pesar de ser tradicionalmente considerada una piedra diferenciada del marés en general, se trata también de una calcarenita, de fácil obrar y tradicionalmente utilizada en la construcción.

\section{Características generales}

\section{Estructura}

El marés está formado básicamente por consolida- 
ción de granos, entre los que predominan los comprendidos entre 2 y $1 / 16 \mathrm{~mm}$ de grosor (de tamaño o fracción arena). Estas partículas se caracterizan por su forma redondeada (erosión por transporte) y su buena selección lo que les confiere una alta uniformidad de tamaños relacionada con la sedimentación en ambientes eólicos y litorales, lo que hace que la ordenación o empaquetamiento del sedimento sea mayor, resultando así un conjunto homogéneo con pequeños espacios vacíos entre el entramado de partículas.

De todo ello resulta un sistema poroso tridimensional, más o menos continuo, de cavidades y canales capilares. Normalmente estos espacios están intercomunicados (porosidad abierta), pero una parte puede quedar aislada del sistema general (porosidad cerrada) en función del grado de cementación.

El cemento que une las partículas normalmente es de tipo esparítico. La matriz suele ser inexistente o poco importante, principalmente en el marés de origen eólico.

De forma general, dentro de la clasificación de rocas carbonáticas, se puede considerar al marés como un grainstone (roca carbonática granosoportada, sin matriz) bioclástico (u oolítico en el caso de la piedra de Santanyí). Más raramente, algunos tipos de marés pueden presentar una estructura pakcstonewackestone (roca carbonática formada por un mínimo de un $10 \%$ de granos aloquímicos y el resto por matriz fina) con un componente más elevado de matriz intergranular. Otros tipos de marés, definidos vulgarmente como arcillosos, pueden ser calcisiltíticos con predominio de partículas más pequeñas de tamaño limo $(<1 / 16 \mathrm{~mm})$.

Para la determinación de la granulometría específica de cada tipo de marés se ha seguido la clasificación de carbonatos Udden-Wentworth.

\section{Caracterización química y mineralógica}

Se trata de un material formado en más del $90 \%$ por carbonato cálcico $\left(\mathrm{CaCO}_{3}\right)$ y el resto por componentes diversos como el magnesio, el aluminio, la sílice y el hierro, los cuales conforman menos del $10 \%$ del material y se encuentran en porcentajes diferentes en función del origen sedimentológico y la zona geográfica de extracción de la piedra. Estos minerales son los responsables de establecer variaciones dentro de las características homogéneas del material, todo ello de acuerdo con cual sea la relación porcentual entre ellos.

Normalmente, el carbonato cálcico se presenta en forma de aragonito (forma alotrópica más inestable) y calcita en el marés de formación más moderna, y en forma de calcita (forma alotrópica más estable) en el marés de formación más antigua. En ocasiones, algunos de los componentes pueden estar parcial o totalmente dolomititzados (sustitución del carbonato cálcico por dolomita).

Los componentes clásticos de la fracción arenita se encuentran cohesionados por cemento carbonático (calcita) de origen diagenético, y el grado de cementación determinará la mayor dureza o fragilidad de la roca en su conjunto.

La presencia de granos de cuarzo es mucho más abundante en el marés de formación eólica que en el marés sedimentado en ambientes marinos.

Algunos tipos de marés más arcillosos, como los extraídos de las formaciones más calcisiltíticas, tienen una mayor abundancia de minerales de la arcilla (caolinita, illita, etc.).

\section{Caracterización física-mecánica}

Los principales parámetros físicos y mecánicos de interés en el marés (ver valores en Anexo I) son los que se definen a continuación:

- Densidad aparente o densidad de la roca seca, definida como la masa del material seco por unidad de volumen total de roca, es decir, el volumen incluyendo la parte sólida y todos sus espacios vacíos. En general el marés presenta una baja densidad aparente $\left(\sim 1,70 \mathrm{~g} / \mathrm{cm}^{3}\right.$ frente a los $2,70 \mathrm{~g} / \mathrm{cm}^{3}$ del hormigón por ejemplo).

- Coeficiente de absorción o coeficiente de absorción de agua por capilaridad, que se define como el peso de una muestra saturada de agua en relación (\%) en peso de la misma muestra desecada. De forma general, el marés presenta un elevado coeficiente de absorción ( $13 \%$ frente al $0,55 \%$ de la piedra caliza de Binissalem).

- La resistencia a la compresión, a la flexotracción y al impacto son parámetros que hacen referencia a las propiedades mecánicas de resistencia de la roca a la fractura por presión, flexión e impacto respectivamente. En general, el marés presenta una baja resistencia (con una media de aproximadamente $140 \mathrm{~kg} / \mathrm{cm}^{2}$ de resistencia a la compresión frente a los 620 $\mathrm{kg} / \mathrm{cm}^{2}$ de la piedra de Binissalem).

- La porosidad abierta, también conocida como porosidad accesible o comunicada, se define como el volumen de poros abiertos o comunicados entre sí y con el exterior (accesibles al agua) por unidad de volumen total de la roca. La porosidad abierta es el parámetro más signi- 
ficativo de las rocas industriales, ya que condiciona su capacidad para almacenar fluidos, influyendo en las demás propiedades físicas, así como en su actividad química y, en última instancia, en su durabilidad y calidad. El marés presenta generalmente una gran porosidad abierta con conductos intercomunicados que le permiten absorber y eliminar agua rápidamente $(\sim 30 \%$ frente al $1,50 \%$ de la piedra de Binissalem). Esta elevada porosidad, influye en el grado de dureza de la piedra, cuando no estan rellenos sus poros por cemento, aumentando su permeabilidad. Esta mayor permeabilidad favorecería la posible circulación de fluidos que si son de carácter ácido podrían alterar estas calizas, debido a la vulnerabilidad de las rocas carbonáticas al contacto con este tipo defluidos.

Hay que distinguir por tanto la denominada porosidad abierta de la porosidad total. Esta última tiene en cuenta la totalidad de espacios vacíos independientemente de que estén intercomunicados o no. Ambas porosidades vienen expresadas en \% en volumen.

El color del marés es variado, oscilando del blanco casi puro (cantera de Cas Busso en Llucmajor y el marés de Muro), blanco cenizo (piedra de Santanyí), color arena amarillento (canteras de s'Arenal), anaranjado (marés "de Porreres") y rojizo (variedades de marés de Manacor y Petra). Naturalmente, el color es muy variable y depende de los componentes de la roca y de la posición de los estratos que la contienen; especialmente si están en relación con la primera capa de cantera (piel), habitualmente en contacto directo con suelos rojos.

En el presente trabajo, la determinación de colores específicos se ha hecho a partir de muestras de fractura fresca comparadas con la carta Munsell ${ }^{\circledast}$ de colores Geological RockColor Chart 2009.

De forma general, se puede decir que el marés de colores más rojizos pertenece a areniscas formadas en ambientes subaéreos (facies continental eólica), mientras que el de colores amarillos o blancos suele corresponder a areniscas que se han formado dentro del mar en ambientes marinos litorales (facies marinas).

En cuanto a la dureza, el marés ha sido considerado tradicionalmente una roca calcárea blanda o muy blanda (densidad 1,4 a $2,1 \mathrm{~g} / \mathrm{cm}^{3}$ ) pero algunos tipos y variedades de marés recristalizadas y/o dolomitizadas pueden llegar a ser realmente duras.
La dureza varía mucho de un tipo de marés a otro. Inclusive dentro de un mismo tipo de piedra, la dureza también varía bastante, no sólo de una cantera a otra, sino también dependiendo del grado de cementación del estrato concreto que se esté cortando en la cama o frente de cantera. Podemos encontrar vetas de marés muy duras y compactas y a continuación, un poco más abajo o lateralmente, aparecer otra de dureza ínfima. Esta variabilidad hace que el marés sea un material difícilmente homologable. Habitualmente el marés de aspecto terroso y/o amarillento (calcisiltitas) es el de dureza más baja.

La primera capa de la cantera (piel) suele ser también muy dura, debido a la iluviación y precipitación de minerales que el agua de lluvia arrastra del suelo al sistema poroso del marés.

Debido a la variabilidad del material, resulta difícil poder establecer unos valores absolutos para los diferentes parámetros físicos de los diferentes tipos de marés, por lo cual, en este estudio se ha optado, a modo indicativo, por trabajar con unos valores teóricos para cada tipo de marés, obtenidos a partir del tratamiento (medias aritmèticas) de los datos disponibles (ver Anexo 1) en la bibliografía técnica existente (Gibert, 1997; Moreno and Muñoz, 1988; Amengual and Sierra, 2008; Sánchez-Cuenca, 2010).

A modo de resumen podemos definir el marés, en general, como un material constituido principalmente por carbonato cálcico, de una alta porosidad, en general muy blando y de una resistencia a compresión muy baja en comparación con otras piedras utilizadas como materiales de construcción. El marés presenta diferencias de textura, porosidad y sobre todo grado de cementación, que le confieren un índice de dureza muy variable, lo que da lugar a diversas variedades que son utilizadas para usos diversos. Esta variabilidad hace que esta piedra arenisca sea un material difícilmente estandarizable y/o homologable.

\section{Clasificación y caracterización específica}

Las diferentes variedades de marés existentes en Mallorca, han sido agrupadas teniendo en cuenta su edad, estratigrafía y características intrínsecas, resultando un total de 8 litotipos (Fig. 1; Tabla 1).

Para cada tipo de marés se describen los siguientes apartados: Concepto.- Definición básica del litotipo dentro del ámbito territorial de la isla de Mallorca; Denominación tradicional.- Nombres comunes tradicionales y/o comerciales; Unidad estratigráfica.Denominación formal del conjunto de estratos de 


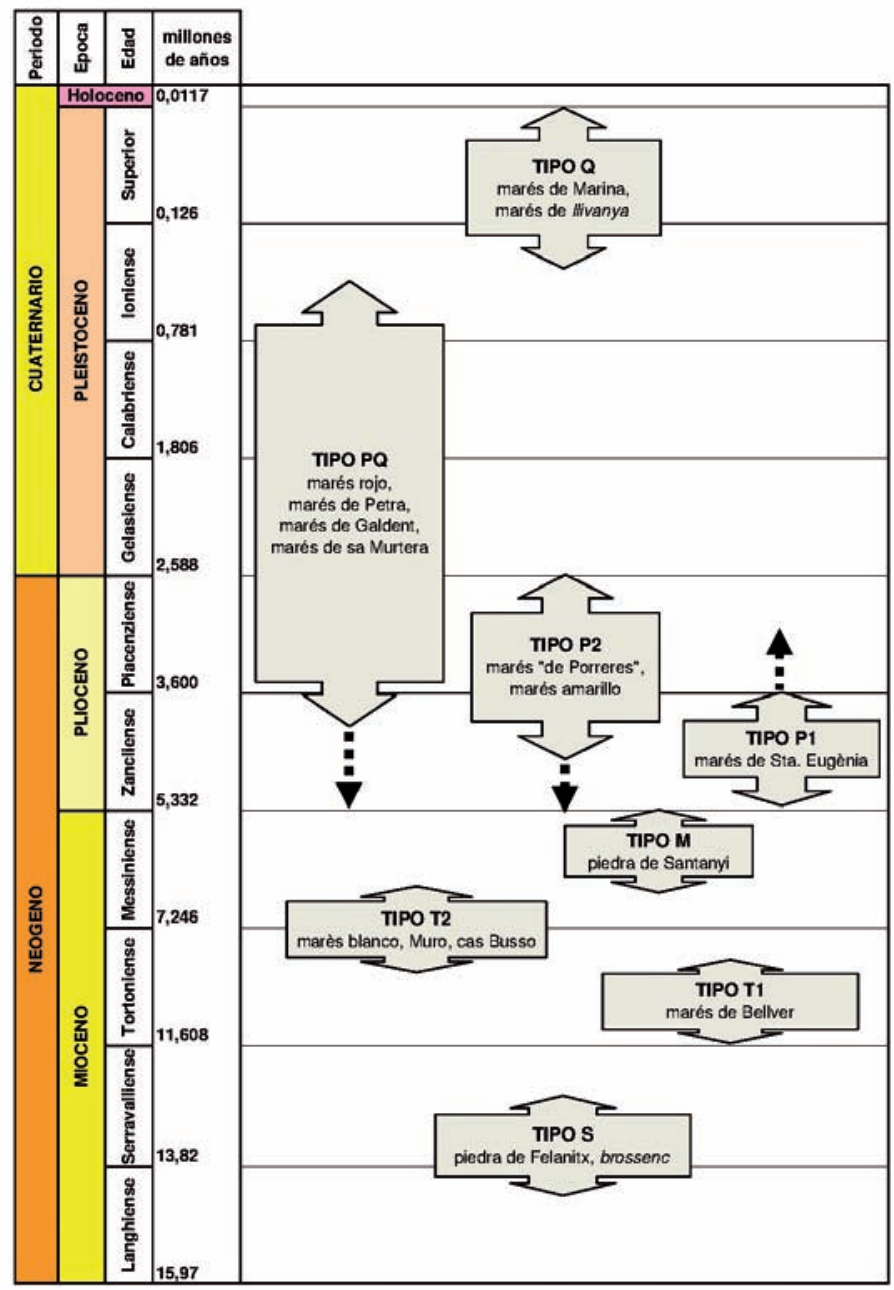

Figura 1. Distribución cronoestratigráfica de los diferentes litotipos de marés.

Figure 1. Chronoestratigraphic distribution of the different lithotypes of mares. procedencia; Edad.- Edad de la roca, indicando, en su caso, el método utilizado para su determinación; Distribución.- Localización geogràfica de las explotaciones dentro de la isla de Mallorca (Ver Anexo II y Fig. 11); Litología.- Composición, estructura y granulometría de la piedra; Paleontología.- Contenido fósil; Ambiente sedimentario.- Paleoambiente (facies) de formación de la roca. Características intrínsecas específicas.- Características petrofísicas más destacadas (color, densidad, porosidad, resistencia, dureza, etc.); Explotaciones tipo.- Principales canteras, con indicación del municipio; Estado de explotación.- Estado actual de la actividad extractora; Observaciones.Usos específicos, aspectos históricos-etnológicos, variedades, etc.

\section{Tipo Q (eolianitas del Pleistoceno medio-superior)}

Concepto. Corresponde al marés eólico, normalmente con laminación (Figs. 2A, 9E, 10A), explotado en el litoral de la isla. Se trata del marés de formación más moderna que se ha explotado en la isla de Mallorca.

Denominación tradicional. Marés de marina, marés de llivanya.

Unidad estratigráfica. Pleistoceno medio-superior. Hemiciclos B y C de Butzer (1975). Sistemas dunares correspondientes a las dos últimas glaciaciones Riss y Würm.

Edad. Cuerda et al. (1982) datan los niveles eólicos de las canteras de es Carnatge-Son Mosson (Palma) dentro del Riss-Würm, correlacionando los mismos con niveles marinos de la línea de costa (Campo de Tiro). Cuerda (1975) indica que las dunas del Riss

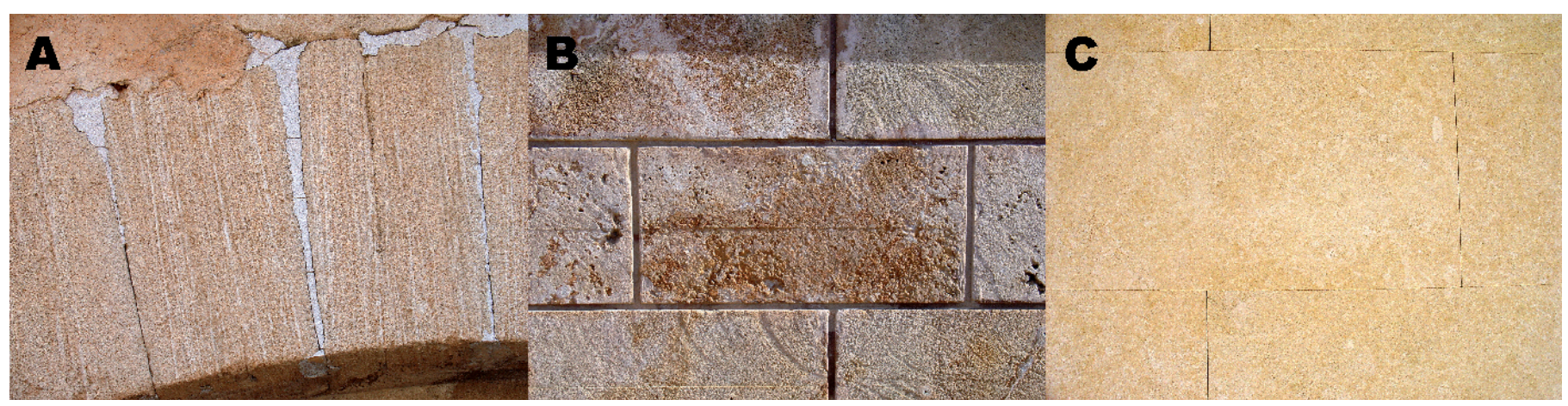

Figura 2. Marés explotado en la cuenca de Campos: A) Marés tipo $Q$, de las dunas consolidadas del litoral, en el que puede apreciarse su laminación característica; B) Marés tipo PO de la cantera de SonToni Amer (Campos); C) Marés tipo $\mathrm{P}_{2}$ de la cantera de Son Grau (Campos). Figure 2. Mares quarried in the Campos basin: A) mares type $Q$, from the consolidated dunes of the litoral, with their characteristic laminations; B) mares type PQ, from the Son Toni Amer quarry (Campos); C) mares type $P_{2}$, from the Son Grau quarry (Campos). 
Mas Gornals, G., 2017. Hacia una tipología de la piedra de marés de Mallorca. Concepto... Boletín Geológico y Minero, 128 (2): $301-328$

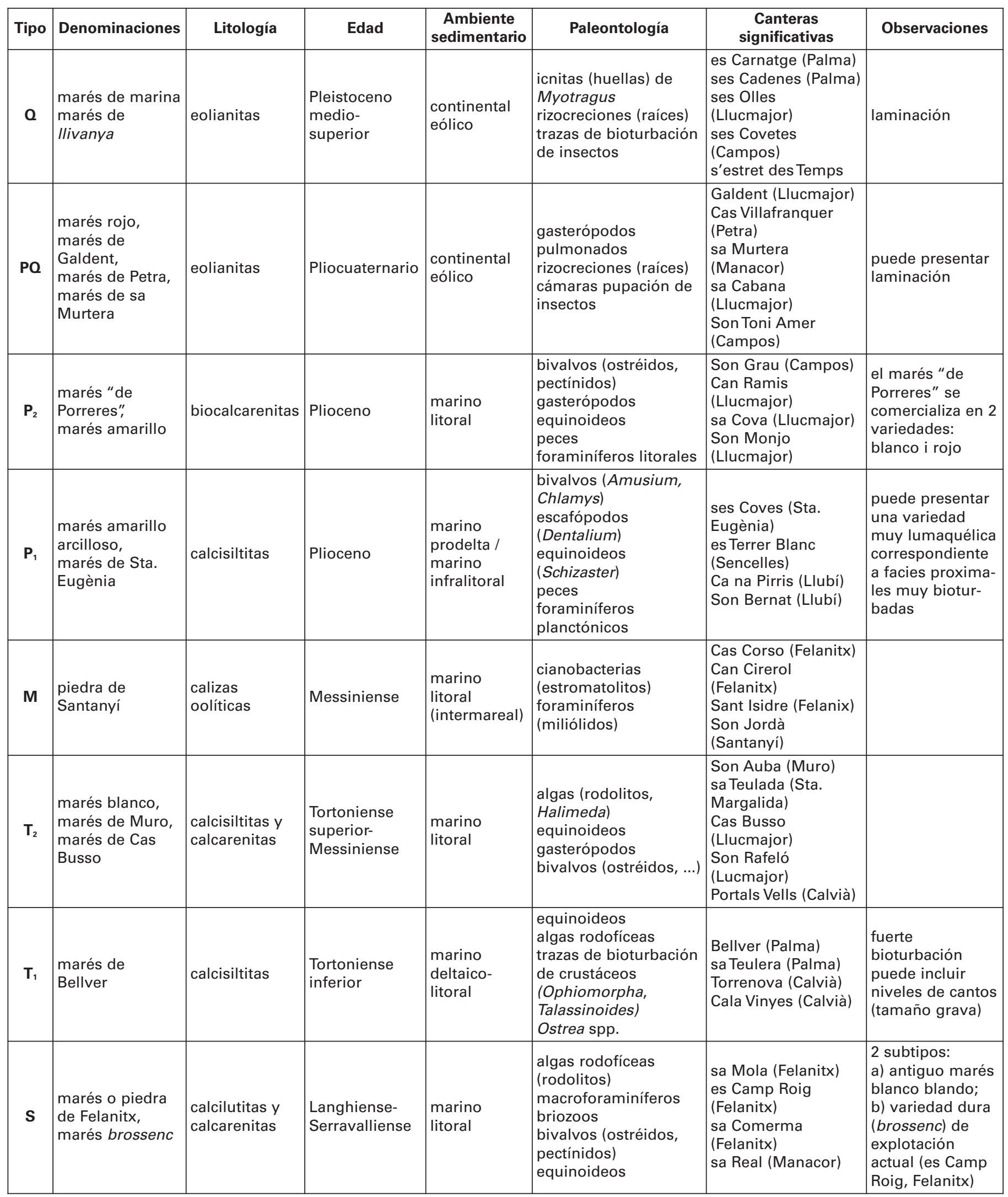

Tabla 1. Clasificación tipológica del marés de Mallorca.

Table 1. Typological classification of the mares of Mallorca. 
( 200.000 años) suelen ocupar una amplia franja costera, penetrando cuando se desplazan sobre las Ilanuras bajas, pero sin llegar a mucha altura. GonzálezHernández et al. (2001) también datan los niveles dunares explotados en las canteras de ses Cadenes y San Francisco (Playa de Palma) como pertenecientes al último y penúltimo estadios glaciares Würm y Riss (80.000-200.000 años). Los sistemas dunares y paleosuelos de las canteras de S'Estret des Temps (Santanyí) han sido fechados mediante técnicas radiométricas $\mathrm{C}^{14}$ (Clemmensen et al., 2001; Fornós et al., 2002) en una edad de 41.000 y 28.980 años, lo que implica que estos depósitos dunares corresponderían al último estadio glacial (Würm, MIS-3) (Fornós et al., 2007).

Distribución. Las antiguas explotaciones las encontramos principalmente en la costa sur i este de la isla pero también en el litoral de la Sierra Norte de la isla (Sant Elm, Escorca, cala Sant Vicenç, etc.), con bastante concentración en el litoral de Palma, Llucmajor, ses Salines y Santanyí (Ver Anexo II y Fig. 11). Las canteras en general son poco extensas pero numerosas, excavadas a cielo abierto sobre las formaciones dunares fósiles en las zonas de costa baja (Palma, Campos, Ses Salines, Alcúdia), los islotes, y formaciones dunares fósiles tipo cliff-front (adosadas) y cliff-top (sobrepuestas) en los acantilados (Andratx, Calvià, Llucmajor, Santanyí).

Litología. Eolianitas carbonáticas formadas por arenas bioclásticas compuestas en más de un $90 \%$ por componentes aloquímicos esqueléticos. También pueden presentar algunos granos de cuarzo en pequeña proporción. La mineralogía es calcítica, aunque puede haber una pequeña proporción $(<10 \%)$ de aragonito y dolomita. La laminación es debida a estratificación cruzada y ondulación por viento (wind ripples). Pueden presentar niveles intercalados de depósitos coluviales y paleosuelos. Las formaciones donde se extrae esta arenisca, presentan un alto grado de clasificación de arenas distribuidas en láminas en ciclos alternantes de arenas finas y gruesas (laminación, Figs. 2A, 9E, 10A). Suele presentar una baja cementación, de tipo vadoso (acaecida sobre la capa freática), alternando láminas con diferente grado de cementación. Predominan los granos de tamaño arena media a muy gruesa $(1 / 4-2,0 \mathrm{~mm})$ bien seleccionados.

Paleontología. Entre los bioclastos destacan los fragmentos de algas coralinaceas, moluscos, equinoideos (púas de erizos de mar), foraminíferos bentónicos y briozoos. Los estratos pueden presentar bioturbación por icnitas (Fig. 9E) del bóvido Myotragus balearicus Bate 1909 (icnoespecie Bifidipes aeolis Fornós et al. 2002), trazas de insectos y rizoconcreciones.
Ambiente sedimentario. Sistemas dunares y paleosuelos interestratificados en las dunas. La variación rítmica observada en las diferencias de cementación (laminación) puede ser atribuida a variaciones estacionales (alternancia de períodos húmedos-secos) características del clima de la región mediterránea (Fornós et al., 2002).

Características intrínsecas específicas. Normalmente presenta un color anaranjado muy pálido (10YR 8/2) y elevada porosidad inter e intrapartícula. No se han encontrado datos cuantitativos sobre las características petrofísicas específicas de este tipo de marés.

Explotaciones tipo. Es Carnatge, ses Cadenes (Palma); ses Olles, $\mathrm{Na}$ Caretes (Llucmajor); ses Covetes (Campos); s'Estret des Temps, ses Piquetes (Santanyí); es Ras (Felanitx); es Frontó des Molar (Manacor); Manresa (Alcúdia).

Estado explotación. Actualmente sólo queda una cantera en proceso de abandono en la zona posterior de la Playa de Palma. Las canteras de la orilla del mar ya no se explotan.

Observaciones. Se caracteriza por una clara estratificación que facilitaba la extracción de piezas de poco espesor $(5-3 \mathrm{~cm})$ denominado marés de llivanya (arenisca de lanchas) utilizado para la construcción de medianeras, pavimentos y techumbres, en este último caso dispuestas sobre las vigas y posteriormente cubiertas por las tejas. Antiguamente era transportado por vía marítima hasta Palma donde los sillares eran descargados a pie de muralla para su venta y distribución en los diferentes lugares de construcción (Habsburg-Lothringen, 1871; Rosselló, 1964; Vich, 2006).

\section{Tipo PQ (eolianitas del Pliocuaternario)}

Concepto. Engloba el marés eólico correspondiente a formaciones dunares del Pleistoceno inferior $y$ de las facies eólicas regresivas del Plioceno (Figs. 2B, 3).

Denominación tradicional. Marés rojo, marés común, marés de Petra, marés de Galdent.

Unidad estratigráfica. Facies eólicas de la Formación Calcarenitas de Sant Jordi (Pomar et al., 1983). Hemiciclos D, E y F de Butzer (1975). Sistemas dunares correspondientes a las primeras glaciaciones pliocenas hasta la glaciación Mindel.

Edad. Pleistoceno inferior-Plioceno s.l. $(\sim 3,6-0,8$ Ma). Las dunas fósiles muy alejadas de la costa y/o situadas alturas del orden de los $100 \mathrm{~m}$ o más, deben considerarse como correspondientes al Pleistoceno inferior o más antiguas (Cuerda, 1975). Colom et al. (1968), Cuerda et al. (1969) y Rosselló (1971) se refie- 


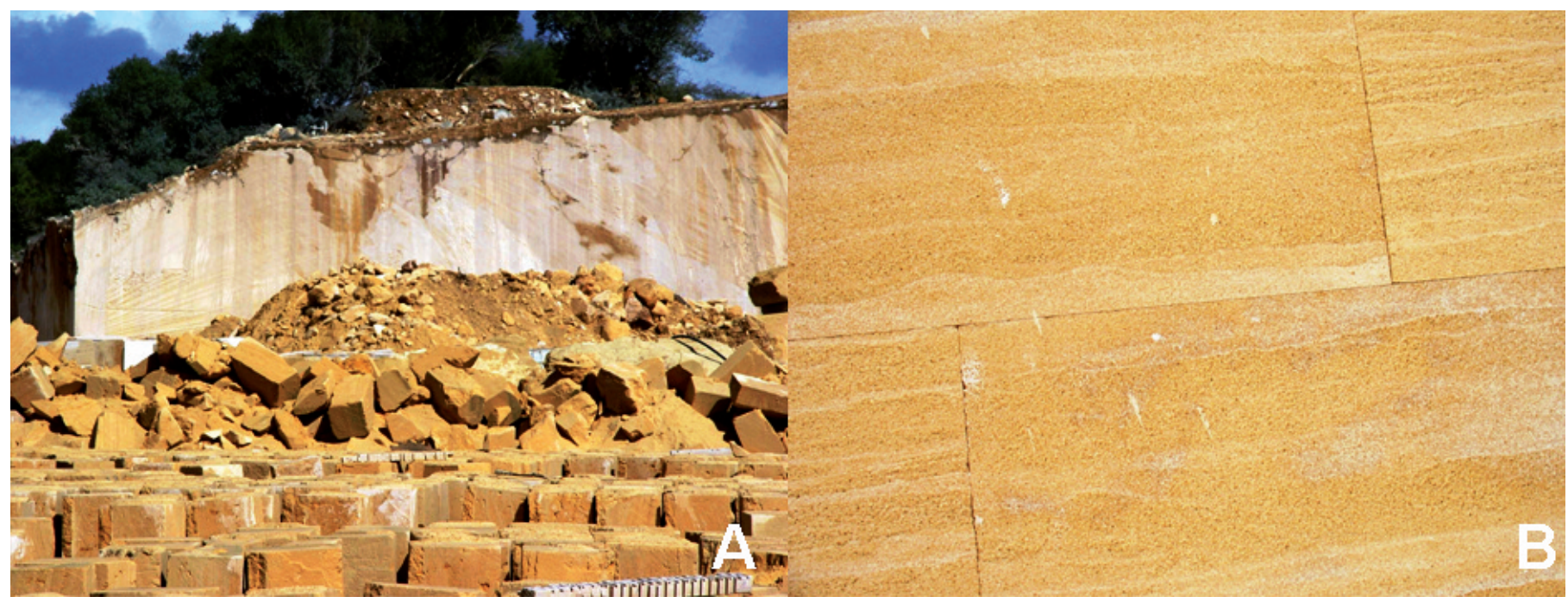

Figura 3. A) Frente de corte con hilo diamantado y B) detalle del marés tipo PQ de la cantera de sa Sínia Nova (Manacor), el cual destaca por su dureza que puede llegar a admitir el pulido.

Figure 3. A) Quarry front cut by diamond wire and B) detail of mares type PQ, from sa Sínia Nova quarry (Manacor), noted for its hardness which withstands polishing.

ren expresamente a los depósitos dunares situados a 150-160 m de altitud en Llucmajor (Galdent, Son Fullana, Son Mulet, Son Lluís) y Campos (Son Grau) como un paleolitoral plioceno de terrazas marinas $y$ dunas.

Distribución. Plataforma de Llucmajor, cuencas de Palma, Campos y Alcúdia-Sa Pobla, y zona de Petra (Ver Anexo II y Fig. 11). Algunas explotaciones en la zona de Santa María del Camí y cubeta de Manacor. Situadas desde cerca de la costa y hasta alturas de $220 \mathrm{~m}$ hacia el interior de la isla.

Litología. Eolianitas, de tonos anaranjados o rojizos. Presentan estratificación cruzada a gran escala y ángulo y bioturbación por rizoconcreciones. Pueden presentar niveles intercalados de depósitos coluviales y paleosuelos en forma de limos rojos. Normalmente contienen una pequeña proporción de granos de cuarzo. Algunas areniscas de este tipo como la de sa Sínia Nova (Manacor) pueden presentar cierta dolomitización $(0,4 \%$, Amengual and Sierra, 2008). Presenta un grano de tamaño arena media a gruesa $(1 / 4-1,0 \mathrm{~mm})$, normalmente bien seleccionado.

Paleontología. Entre los bioclastos que lo componen destacan los foraminíferos litorales (Fig. 4), así como fragmentos de algas, de equinoideos y de moluscos, resedimentados. Normalmente presentan rizoconcreciones, gasterópodos pulmonados y cámaras de insectos (Mas and Ripoll, 2010; Mas, 2013), más abundantes en las zonas adyacentes a los niveles de paleosuelos.
Ambiente sedimentario. Sistemas dunares, formados en periodos de clima seco, y paleosuelos de alteración, correspondientes a períodos más húmedos. La acumulación de estos depósitos dunares interiores coincidiría con episodios regresivos, correspondientes a retiradas del mar. La concentración de aguas en forma de hielo en los polos durante las glaciaciones pliopleistocenas habría provocado las consecuentes retiradas del mar dejando emergidas extensas áreas de fondos marinos arenosos que serían acumulados por la acción del viento en forma de dunas que avanzaban hacia el interior de la isla (Cuerda, 1975). Estas acumulaciones pueden presentar gran potencia en forma de importantes depósitos dunares adosados al relieve preexistente como ocurre en Galdent (Llucmajor); Son Toni Amer, Can Banyeta (Campos); Cas Villafranquer (Petra); sa Murtera, sa Sínia Nova (Manacor).

Características intrínsecas específicas. Normalmente presenta colores entre naranja muy pálido (10YR $8 / 2)$ y naranja moderadamente rojo (10R $6 / 6$ ). En general, destaca por su elevada porosidad abierta y baja dureza. Ver valores cuantitativos en el Anexo I.

Explotaciones tipo. Son Mulet, Galdent (Llucmajor), Cas Villafranquer, Can Bon Jesús (Petra), es Figueral, Can Banyeta, SonToni Amer (Campos), sa Murtera, sa Sínia Nova (Manacor).

Estado explotación. Existen bastantes canteras en activo. Se trata de un tipo de marés muy utilizado tanto antiguamente como en la actualidad. 
Observaciones. El de Galdent (Llucmajor) es un marés de calidad o marés bo (bueno), formado en un ambiente eólico, de grano medio a grueso, muy homogéneo, duro y con gran demanda para la construcción de acabados, arcos, ventanas, esquineras, etc.

El marés de Son Toni Amer (Campos) es un marés brescat que se caracteriza por presentar muchas rizoconcreciones (estructuras de raíces fósiles) e inclusiones arcillosas rojas (Fig. 2B).

Algunas areniscas de este tipo, como las de sa Murtera y sa Sínia Nova (Manacor), presentan un aspecto finamente laminado (peinado) (Fig. 3). Las piezas de marés correspondientes a niveles fuertemente recristalizados y duros de la cantera de sa Sínia Nova han llegado a admitir incluso el pulido.

Algunas canteras de marés tipo $\mathrm{PQ}$ pueden explotar también, sus niveles más inferiores, correspondientes al marés marino tipo $\mathrm{P}_{2}$ (Can Casetes, Son Grau-Son Oliver), ya que el tránsito de niveles marinos y playas $\left(P_{2}\right)$ a los niveles eólicos $(P Q)$ está constituido por una secuencia normal regresiva (retirada del mar).

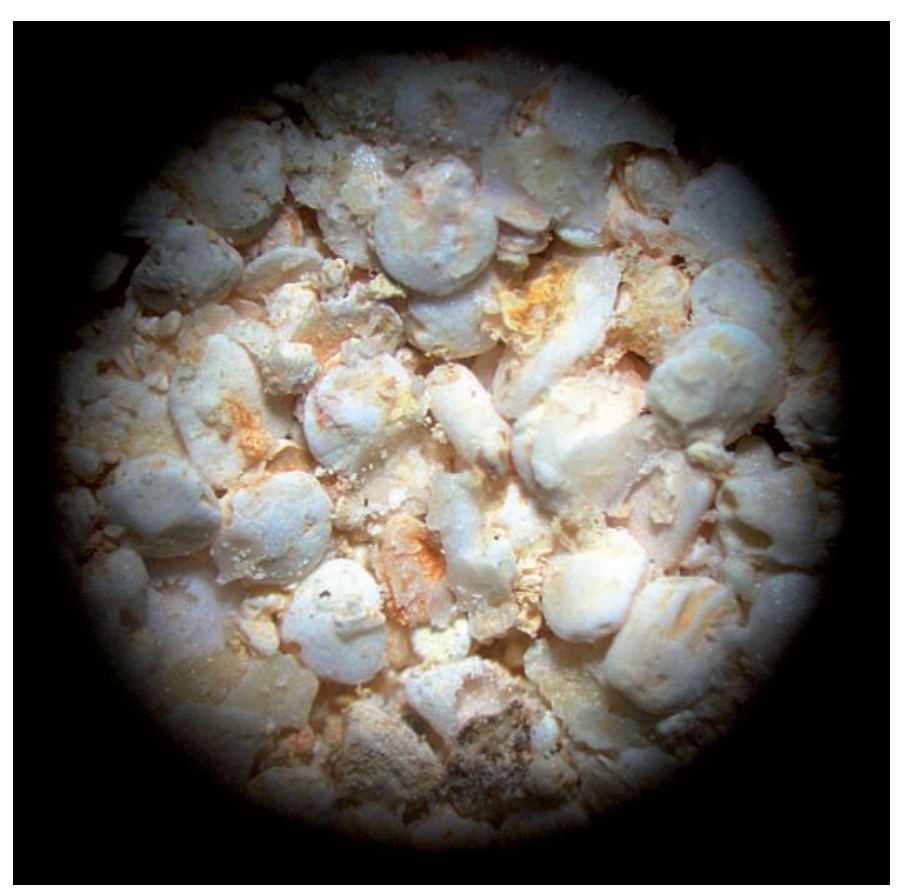

Figura 4. Microfotografía (lupa binocular) de Marés tipo PO en la que pueden apreciarse los esqueletos de foraminíferos. Diámetro círculo $5 \mathrm{~mm}$.

Figure 4. Microphotograph (binocular microscope) of mares type $P Q$, in which foraminifera skeletons appear. Circle diameter $5 \mathrm{~mm}$.

\section{Tipo $\boldsymbol{P}_{2}$ (biocalcarenitas marinas del Plioceno)}

Concepto. Marés correspondiente a las facies marinas calcareníticas del Plioceno (Fig. 2C).

Denominación tradicional. Marés "de Porreres" y marés amarillo de Llucmajor.

Unidad estratigráfica. Facies marines de la formación Calcarenitas de Sant Jordi (Pomar et al., 1983).

Edad. Plioceno medio-superior ( 3,6-2,5 Ma). Cabe tener en cuenta que algunos depósitos calcareníticos litorales pliocenos (Calcarenitas de Sant Jordi) situados a más altura, en los márgenes de las cuencas, pueden ser cronoestratigráficamente equivalentes a los depósitos calcilutíticos profundos (Calcisiltitas de Son Mir, Pomar et al., 1983) situados en los depocentros de las cuencas (Mas, 2011a), pudiendo corresponder en este caso al Plioceno inferior (5,3 Ma).

Distribución. El marés o piedra "de Porreres" (Fig. 2C) proviene de las canteras subterráneas del complejo Son Grau-Son Oliver-Son Rossinyol, situadas al $\mathrm{N}$ de la cuenca de Campos, mientras que el marés amarillo se explota en un conjunto de canteras a cielo abierto que se sitúan en la parte oriental de la cuenca sedimentaria de Palma, dentro del término municipal de Llucmajor en los alrededores de la línea divisoria con el término municipal de Palma (Torrente des Jueus-Torrente de Son Monjo-Barranco de Can Casetes) (Ver Anexo II y Fig. 11).

Litología. Biocalcarenitas de aspecto masivo y muy bioturbadas. Normalmente contienen una pequeña proporción granos de cuarzo. Puede aflorar también una lumaquela masiva (rudstone) de bivalvos y otros moluscos, de los que únicamente se conserva el molde, a excepción de los ostreidos y pectínidos (copinyat). Presentan estratificación cruzada y una elevada porosidad. La base puede constituir una transito gradual hacia capas calcilsiltíticas $\left(P_{1}\right)$ o consistir en una lumaquela transgresiva sobre materiales pre-pliocenos (principalmente sobre el Messiniense). La granulometría es de arena muy fina a media (1/6$1 / 2 \mathrm{~mm}$ ), con el grano muy bien seleccionado.

Paleontología. Puede contener restos de algas calcáreas, foraminíferos litorales (Ammonia, Cibicides, Elphidium), ostrácodos, pectínidos, gasterópodos y otros moluscos, corales solitarios, equinoideos, crustáceos, peces (Mas, 2000) y restos de mamíferos marinos (Mas, 2004). Los niveles de lumaquela (copinyat) están formados por moldes de moluscos, sobre todo bivalvos (conchas) y algún gasterópodo que le confieren una gran porosidad móldica. Debido a la disolución normalmente sólo se conservan las conchas calcíticas (ostreidos, pectínidos), habiéndose disuelto totalmente las aragoníticas (demás bivalvos y moluscos). Corresponden a niveles de playas en las 
que normalmente son identificables bivalvos (cardítidos, Ostrea spp., Pecten sp., Callista italica, Panoplea glycimeris, Gari labordei), gasterópodos (Strombus coronatus [Fig. 9C,D], Conus sp.) y dientes de peces.

Ambiente sedimentario. En general corresponde a una secuencia marina litoral regresiva con facies deltaicas y niveles de playas (depósitos shoreface y foreshore).

Características intrínsecas específicas. El denominado marés "de Porreres" presenta colores que van del naranja muy pálido (10YR $8 / 2$ ) al rosa moderadamente anaranjado (5YR 8/4), mientras que el marés amarillo presenta un color amarillo grisáceo (5Y 8/4). Destaca por su alta porosidad abierta y capacidad de absorción. Se trata de un material en general muy blando. Ver valores cuantitativos en el Anexo I.

Explotaciones tipo. Molar de Cala Pi, Can CasetesCan Ramis, sa Cova, Son Monjo (Llucmajor); Son Grau, Son Oliver (Campos).

Estado explotación. Actualmente sólo existen dos explotaciones en activo, Son Grau en Campos y Can Casetes-Can Ramis en Llucmajor.

Observaciones. El denominado marés "de Porreres" realmente proviene del término municipal de Campos, de las canteras de Son Grau-Son OliverSon Rossinyol. Contrariamente a lo que su nombre indica, el marés o piedra "de Porreres", nunca ha sido explotado dentro del término municipal de Porreres y su atribución a este municipio probablemente se deba a que el acceso a las canteras siempre se ha hecho desde de un camino que sale del núcleo urbano de Porreres (camino de ses Pedreres) o/y que los trabajadores de estas canteras han sido casi siempre de este municipio.

Se trata de un marés rosado de grano fino y compacidad regular pero muy absorbente que con el tiempo toma una pátina de color gris que le cierra los poros y lo hace menos permeable. Esta piedra, que se extrae en grandes bloques de las canteras subterráneas de Son Grau, por su finura y facilidad de obrar (Fullana, 1974), ha sido muy empleada en Mallorca en la construcción de fachadas, molduras, balcones, etc. Este tipo de piedra arenisca lo podemos encontrar en las fachadas de algunos edificios emblemáticos del modernismo en Palma como el Círculo Mallorquín o el Gran Hotel (Sánchez-Cuenca 2010).

Actualmente el marés de Son Grau (Campos) se comercializa en dos variedades de color, Porreres blanco (color 10YR 8/2) y Porreres rojo (color 5YR 8/4).

En Son Monjo (Llucmajor) se explotaron con fines ornamentales unas piezas de un marés muy aconchado (acopinyat) correspondiente a los niveles de lumaquela (rudstone) de moldes de moluscos. También en la cantera de sa Punta de sa Dent o Molar de Cala Pi
(Llucmajor) niveles más finos y duros de esta lumaquela pliocena (Mas et al., 2013), confundida en ocasiones con depósitos messinienses (Pomar et al., 1983; Mateos et al., 2011), fueron explotados durante épocas pretéritas para la elaboración de muelas de molino y más recientemente, en la década de 1960, mediante corte mecánico para la obtención de piezas con fines ornamentales (lumaquela). Aunque inicialmente la explotación antigua de muelas de molino fuese atribuida a la época romana (Muntaner, 1959; Mateos et al. 2011), recientemente algunos autores han defendido que la explotación original podría ser de época andalusí (J. Sánchez-Navarro, comunicación personal).

Algunas canteras de arenisca tipo $\mathrm{P}_{2}$ pueden explotar también, a sus niveles superiores, marés eólico de tipo PO (Can Casetes, Son Grau, Son Oliver), ya que el tránsito de niveles marinos y playas $\left(\mathrm{P}_{2}\right)$ a los niveles eólicos (PQ) superiores, está constituido por una secuencia normal regresiva (retirada del mar).

Rosselló (1971) indica que este tipo de piedra arenisca ha sido explotado desde hace siglos debido a su alta calidad, y que en las canteras de Son Mulet (Llucmajor) y Son Grau (Campos) se buscó particularmente el nivel inferior (marino), de mejores prestaciones para la construcción, mediante galerías subterráneas, que en el caso de la segunda cantera llegan a tener varios kilómetros de recorrido.

La importancia de las explotaciones y la calidad del marés $\mathrm{P}_{2}$ de las canteras de Son Grau-Son OliverSon Rossinyol (Campos) llego a determinar la ubicación de la estación de tren denominada Canteras, desde donde se cargaba y distribuía este material constructivo hacia la capital Palma y otros pueblos de la isla.

\section{Tipo $\boldsymbol{P}_{1}$ (calcisiltitas marinas del Plioceno)}

Concepto. Se trata de un marés amarillo muy limoso (de grano muy fino), normalmente de baja consistencia, constituido básicamente por calcisiltitas correspondientes a las facies más profundas de los sedimentos pliocenos. Este marés presenta dos subtipos que pasan gradualmente de un marino calcisiltítico muy fino (correspondiente a facies más profundas) a un marés lumaquélico más grosero pero que conserva la matriz calcisiltítica, correspondiente a facies más proximales (Fig. 10B).

Denominación tradicional. Marés amarillo arcilloso, marés de Santa Eugenia.

Unidad estratigráfica. Formación Calcisiltitas de Son Mir (Pomar et al. 1983), denominada también Margas con Amusium (García-Yagüe and Muntaner, 1968). 
Edad. Se considera que la edad de estos niveles es Plioceno inferior ( 5,3-3,6 Ma) en base a su contenido en microfauna de foraminíferos (Colom, 1980, 1985), biozonas N18-N19 de Blow (Alvaro et al., 1984). El marés $P_{1}$ extraído de los niveles superiores de grano más grueso y más lumaquélicos, puede ser cronoestratigráficamente equivalente al tipo $\mathrm{P}_{2}$ (Plioceno medio-superior).

Distribución. Las canteras se ubican básicamente en los niveles que afloran en la cuenca de Inca (Ver Anexo II y Fig. 11), en las inmediaciones de la denominada falla de Sencelles (Santa Eugenia, Biniali, Sencelles, Llubí, torrente de Vinagrella). Esta distribución posiblemente se debe a que el movimiento de desplazamiento de la falla ha facilitado el afloramiento de estos niveles de calcisiltitas, que normalmente sólo aparecen en sondeos en zonas más profundas de la cuenca sedimentaria (Mas et al., 2014).

Litología. Calcisiltitas de color amarillo a amarillo pálido muy característico. Normalmente presenta un aspecto masivo (Fig. 10B) con niveles removidos por la acción de organismos (bioturbación) pero también pueden presentar niveles con pasadas cíclicas detríticas que le confieren un aspecto más laminado. Las valvas de Amusium pueden encontrarse en posición horizontal siguiendo la estratificación o bien localmente fragmentadas por carga. Los niveles lumaquélicos presentan fuerte bioturbación. Normalmente presenta un tamaño de grano de arena muy fina (1/16-1/8 $\mathrm{mm})$ a limo $(<1 / 16 \mathrm{~mm})$.

Paleontología. Se caracteriza por la presencia de abundantes bivalvos pelágicos (Amusium, Neopycnodonte), pequeños pectínidos (Chlamys), escafópodos (Dentalium), briozoos, braquiópodos (Terebratula), equinoideos (Schizaster), restos de peces y gran cantidad de foraminíferos planctónicos (básicamente globigerínidos) y bentónicos que son los componentes mayoritarios de la roca (Morey and Mas, 2009).

Ambiente sedimentario. Corresponden a una sedimentación detrítica en facies de plataforma distal profunda en una cuenca abierta subsidente. Constituye un complejo deltaico (facies distales prodelta) alimentado básicamente por la denudación del relieve de las sierras (Alvaro et al., 1984; Simón and Ramón 1986). Los niveles lumaquélicos corresponderían a facies más proximales (menos profundas) de la zona infralitoral o anteplaya.

Características intrínsecas específicas. Generalmente es de color amarillo grisáceo (5Y 8/4). Se trata de un material poroso muy blando. No se han encontrado datos cuantitativos sobre las características petrofísicas específicas de este tipo de marés.

Explotaciones tipo. Ses Coves, Son Palou, es
Monument (Santa Eugenia); camino del Terrer Blanc (Sencelles), Ca na Pirris, Can Planxador-Son Bernat (Llubí).

Estado explotación. Actualmente ya no se explota.

Observaciones. Antiguamente los sillares también eran extraídos en pequeñas canteras improvisadas por todas partes allí donde afloran sedimentos practicables mínimamente consistentes (Mas in Morey, 2009).

\section{Tipo M (caliza oolítica del Messiniense)}

Concepto. Caliza oolítica messiniense muy conocida y utilizada tanto en la construcción como en la talla artística (Fig. 5).

Denominación tradicional. Piedra de Santanyí.

Unidad estratigráfica. Pertenece al Complejo Carbonático Terminal (Esteban, 1979), más concretamente a la Unidad Oolítica (Fornós, 1983) de la formación Calizas de Santanyí (Pomar et al., 1983).

Edad. Por su ubicación entre la Unidad Arrecifal (Pomar et al., 1983) y el Plioceno se puede situar esta unidad dentro del Messiniense superior. Mientras que algunos autores (Cornée et al., 2004) sitúan el Complejo Carbonático Terminal entre los 5,94-5,77 millones de años, otros (Bourillot et al., 2010) lo sitúan en una edad entre los 5,6-5,45 millones de años.

Distribución. Explotaciones limitadas a la zona litoral y prelitoral del levante de Mallorca (Ver Anexo II y Fig. 11), entre Portocolom (Felanitx) y Cala s'Almonia (Santanyí).

Litología. Grainstone oolítico o caliza oolítica, clase arenita. Formada principalmente por oolitos unidos por un cemento carbonático que rellena la porosidad intergranular casi completamente (Fig. $5 B)$. Los oolitos u ooides, son gránulos carbonáticos esferoidales de diámetro $<2 \mathrm{~mm}$ con estructura formada por un núcleo detrítico (un grano de cuarzo, un peloide, un fragmento esquelético, un trozo de otro ooide roto) rodeado de una envoltura de láminas carbonáticas concéntricas.

En general los oolitos se encuentran disueltos, conservando-se sólo los moldes en forma de pequeñas esférulas vacías rodeadas del cemento carbonàtico original que rellena los espacios intergranulares.

En estos materiales son frecuentes las estructuras de corriente, principalmente estratificaciones cruzadas (crossbedding) y los niveles de intraclastos en forma de cantos blandos (soft pebbles). En vertical exhibe una secuencia granocreciente (Fornós, 1983; Fornós and Pomar, 1983). Presenta un tamaño de arena muy fina a media $(1 / 16-1 / 8 \mathrm{~mm})$, muy bien seleccionado y muy cementado. 


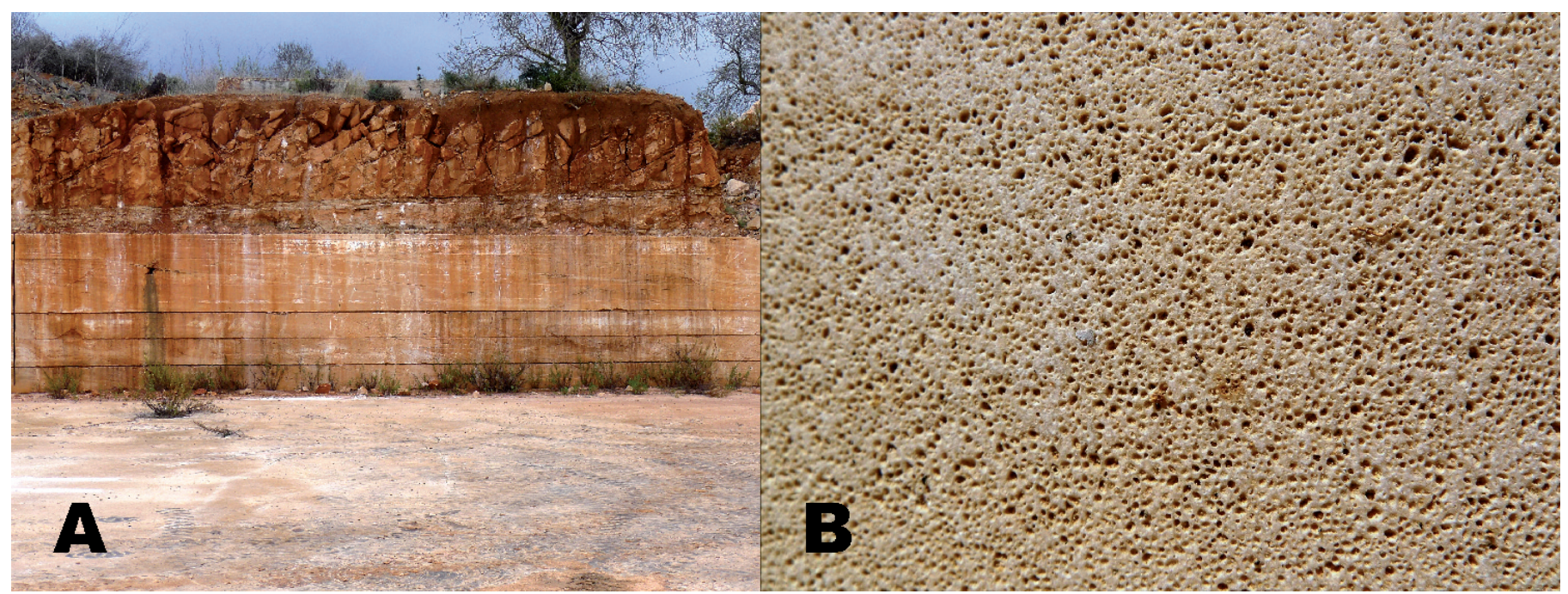

Figura 5. Marés tipo M o Piedra de Santanyí: A) Cantera Sant Isidre (Felanitx); B) Detalle de la porosidad móldica producto de la disolución de los oolitos (la altura de la fotografía corresponde a $15 \mathrm{~mm}$ ).

Figure 5. Mares type M, also denominated Piedra de Santanyí: A) Sant Isidre quarry (Felanitx); B) Close up of moldic porosity produced by dissolution of oolitic grains (The height of the picture corresponds to $15 \mathrm{~mm}$ ).

Paleontología. Estos materiales suelen ser muy pobres en restos fósiles, salvo por la abundancia de estructuras debidas a la acción de cianobacterias (microbialitas) en forma de estromatolitos. Puede presentar microforaminíferos (miliólidos, Ophtalmidium, Ammonia, Glomospira), gasterópodos y ostrácodos (Alvaro et al., 1984).

Ambiente sedimentario. Corresponden a facies litorales e intermareales (sand shoals), que en su conjunto registran un nivel marino pulsante y ascendente, correspondiente a una transgresión marina.

Características intrínsecas específicas. Presentan color gris amarillento (5Y 8/1). A pesar de su alta porosidad total ocasionada por la disolución de oolitos (Fig, 5B), este litotipo destaca sobre todos los demás tipos por presentar una porosidad abierta baja $(\sim 6 \%)$. Se trata por tanto de conductos mal comunicados (moldes aislados de oolitos), que hacen que la roca sea muy poco permeable al agua, siendo también difícil de eliminar una vez a penetrado en el sistema poroso. Presenta una densidad aparente y una resistencia altas. Ver valores cuantitativos en el Anexo I.

Explotaciones tipo. Cas Corso-Sant Isidre-Can Picó, Can Cirerol, Can Gaià (Felanitx), Son Jordà (Santanyí).

Estado explotación. Varias canteras en activo en el municipio de Felanitx. Actualmente sólo queda una explotación en proceso de abandono en el término de Santanyí, población que le ha dado el nombre.

Observaciones. Se trata de una piedra que es muy apreciada para la construcción de acabados y escultura. El frente de la cantera está formado por tramos bien diferenciados, ya que sedimentológicamente los niveles que forman la unidad de Calizas de Santanyí se encuentran perfectamente definidos. De arriba abajo, en explotación podemos distinguir 5 tramos y calidades bien diferenciados (modificado a partir de Ramis, 2013):

1. Roca: Piel de la cantera, muy dura a consecuencia de cementación relacionada con infiltraciones de suelos suprayacentes. Espesor habitual de varios milímetros hasta $3-5 \mathrm{~cm}$. Ocasionalmente se pueden encontrar bloques de buen espesor, de hasta $1 \mathrm{~m}$;

2. Randat. Poroso, estratos con pequeños alvéolos irregulares (Keystone vugs) que le confieren una gran porosidad mòldica (fenestrae) por disolución de intra-clastros, con un espesor de unos $10-25 \mathrm{~cm}$, hasta $1 \mathrm{~m}$;

3. Piedra fina: Piedra homogénea, perfecta para la talla delicada. Utilizada tradicionalmente en trabajos de talla;

4. Favat: Semejante al randat, pero en este caso se conservan los cantos blandos originales (grainstone oolítico con intraclastos), lo que le da aspecto de turrón. El nombre viene de la forma ovalada de los cantos blandos que recuerda a la leguminosa (haba o fava en catalàn). Utilizado en exteriores, por ejemplo, en las torres de la Lonja de Palma;

5. Buena: De mayor dureza y homogénea. 
Corresponde a las denominadas facies litorales de secuencias de barras de playa en forma de suaves líneas curvas que marcan las formaciones estromatolíticas y las estructuras de corriente (crossbedding).

El Archiduque Luis Salvador de Austria en su obra Die Balearen (Habsburg-Lothringen, 1871) indica que la piedra de Santanyí fue exportada a Barcelona e incluso hasta Nápoles (Italia). De hecho, la plementería de la cúpula de la Gran Sala del Castel Nuovo de Nápoles, reconstruida por el arquitecto mallorquín Guillem Sagrera (ca.1380-1456), está construida con Piedra de Santanyí.

El Archiduque también indica que esta piedra tiene el defecto de ser muy compacta, lo que dificulta que se le pueda adherir bien la cal (baja porosidad abierta) y sea necesario tener que practicarle surcos para que se le pueda aferrar la cal.

\section{Tipo $T_{2}$ (calcisiltitas y calcarenitas del Tortoniense superior)}

Concepto. Marés blanco de origen marino explotado principalmente en la zona de Muro-Santa Margalida y las marinas litorales de Llucmajor $\mathrm{i}$ Manacor (Figs. 6, 9A,B, 10C).

Denominación tradicional. Marés blanco, marés de Muro, marés de Cas Busso.

Unidad estratigráfica. Facies lagoon (back reef) y distales (talud-plataforma) de la Unidad Arrecifal (Pomar et al., 1983).

Edad. Tortoniense superior-Messiniense (Pomar et al., 1996), Biozona N17 de Blow (Bizon et al., 1973). Aproximadamente 6-7 Ma.

Distribución. Cuencas de Palma y Muro-Santa Margarita. Plataforma de Llucmajor. Litoral y prelitoral de Manacor y Calvià (Ver Anexo II y Fig. 11).

Litología. Corresponden a calcisiltitas y calcarenitas blancas localmente dolomitizadas. Se trata de un packstone-wakestone bioclástico en el que predomina la matriz micrítica sobre el cemento esparítico. Presentan fuerte bioturbación y se disponen en capas mal definidas subhorizontales o con suave buzamiento de $5-10^{\circ}$ (clinoformas). Algunas variedades pueden presentar una fuerte dolomitización (> 50\%, Amengual and Sierra, 2008). Generalmente presenta un grano que puede oscilar de tamaño arena fina hasta muy gruesa $(1 / 8-2,0 \mathrm{~mm})$ mal clasificado.

Paleontología. Contiene foraminíferos planctóni$\cos$ y bentónicos, equinoideos sedimentívoros (Clypeaster [Fig. 9A]), gasterópodos (Conus), ostreidos (Neopycnodonte, Ostrea), pectínidos y moldes de otros bivalvos. Localmente contienen abundantes rodolitos (Fig. 9B y 10C) o acumulación de fragmentos de algas rodofíceas. Ocasionalmente fragmentos de corales y segmentos de Halimeda. Colom (1985) cita expresamente el foraminífero alveólido Borelis melo (Fichtel and Moll, 1798) como característico del marés blanco (molasas) de la zona de Muro. El marés de Cas Busso (Llucmajor) puede presentar un espectacular floatstone de ostras, bien conservadas debido a su composición calcítica, mostrando multitud de valvas seccionadas por el disco que corta la piedra para su extracción.

Ambiente sedimentario. Corresponden a facies de plataforma abierta y talud distal de unos $50-70 \mathrm{~m}$ de profundidad o a facies de laguna arrecifal (back reef). Pomar et al. (1996) distinguen dos litofacies diferentes, una dominada por algas rojas (rhodalgal) y otra para foraminíferos y moluscos (foramol).

Características intrínsecas específicas. Color blanco (N9). En general presenta alta densidad y resistencia. Ver valores cuantitativos en el Anexo I.

Explotaciones tipo. Son Morey, Son Auba, Vinromà (Muro); sa Teulada, Vernissa Vell (Santa Margarita); Cas Busso, Son Rafeló (Llucmajor), Santa Bárbara, sa Gruta (Manacor), Cueva de la Mare de Deu-Portals Vells (Calvià).

Estado explotación. Varias canteras en activo en Santa Margarita, Muro y Llucmajor.

Observaciones. El Archiduque Luis Salvador de Austria en su obra Die Balearen (HabsburgLothringen, 1871) recoge que con el marés blanco extraído de las canteras de la finca de s'Àguila (marina de Llucmajor), propiedad del Marqués de Vivot, se construyó el interior del oratorio-panteón de la finca de saTorre de Llucmajor. También indica que el marés utilizado para construir el edificio de la estación del ferrocarril de Inca procede de las canteras de Vinromà (Muro) y que el marés de Muro-Santa Margarita ha sido ampliamente utilizado para la construcción de edificaciones de esas y otras poblaciones, así como para los arcos de entrada de algunas casas de Palma. Según el mismo Archiduque este tipo de arenisca presenta una dureza media que aumenta a la intemperie.

\section{Tipo $T_{1}$ (calcisiltitas del Tortoniniense inferior)}

Concepto. Marés de calidad media de colores pardos explotado antiguamente en la zona oeste de la cuenca de Palma (Fig. 10D).

Denominación tradicional. Marés de Bellver.

Unidad estratigráfica. Unidad de Calcisiltitas con Heterostegina (Pomar et al., 1983).

Edad. Tortoniense inferior, biozona N16 de Blow (Alvaro et al., 1984). Aproximadamente 10-11 Ma. 


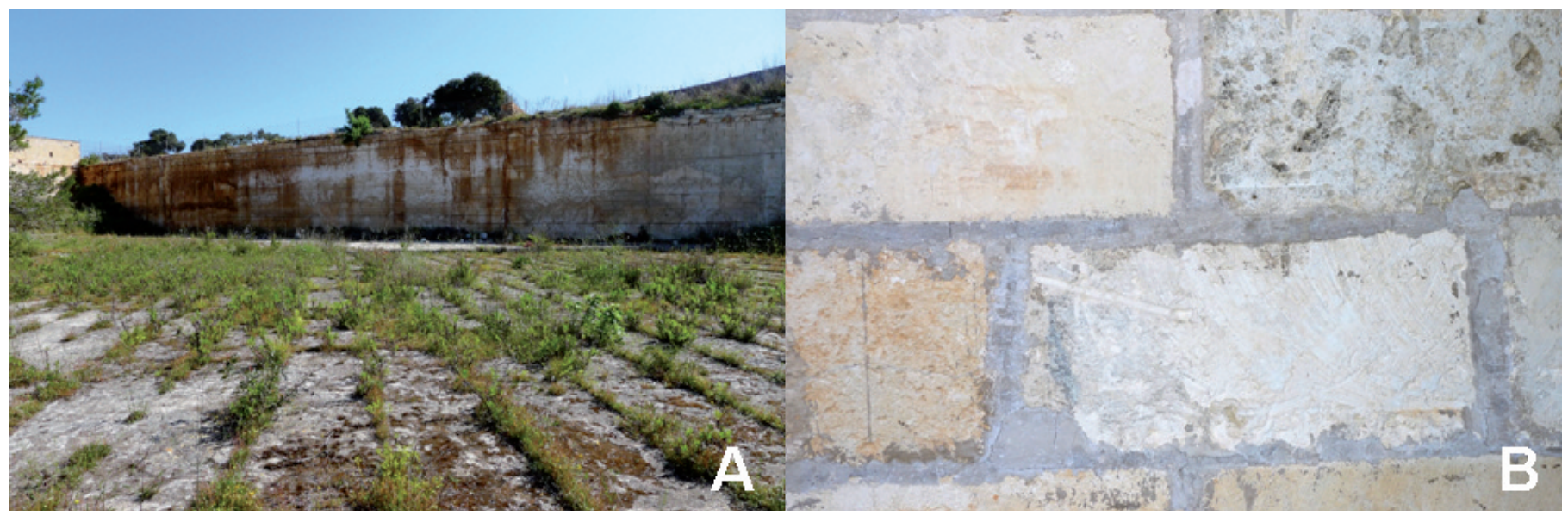

Figura 6. A) Cantera de sa Gruta (Manacor). B) mares tipo $T_{2}$ de la misma cantera.

Figure 6. A) Overview from the sa Gruta quarry (Manacor). B) Blocs of mares type $T_{2}$ from the same quarry.

Distribución. Unas pocas explotaciones en la zona oeste de la ciudad de Palma y en el litoral de Calvià (sector SW de la bahía de Palma, ver Anexo II y Fig. 11).

Litología. Calcisiltitas y calcarenitas bioclásticas con presencia local de niveles de conglomerados y estructuras de estratificación cruzada. Presentan fracturación extensional. El grano normalmente es de tamaño arena muy fina $(1 / 16-1 / 8 \mathrm{~mm})$ a limo $(<1 / 16$ $\mathrm{mm})$. Puede presentar niveles de cantos, tamaño grava (2-64 $\mathrm{mm})$.

Paleontología. Contienen foraminíferos (Heterostegina, Amphystegina, Ammonia, Elphidium, miliólidos), equinoideos (Amphiope bioculata, Clypeaster marginatus, Schizaster sp., Scutela sp.), algas rodofíceas, bivalvos (Ostrea sp., pectínidos), escafópodos, briozoos y dientes de peces. Algunos niveles presentan bastante bioturbación con las icnoespecies Ophiomorpha isp., Thalassinoides isp. y cf. Lapispira isp., correspondientes a galerías excavadas por crustáceos, posiblemente por Callianassa sp. (Gibert et al., 2012).

Ambiente sedimentario. Corresponden a sedimentos marinos de plataforma que presentan a techo una clara secuencia regresiva con clara influencia continental, constituida por depósitos near-shore (playas), que pasan lateralmente a playas de conglomerados (fore-shore) y depositos fan-delta con paleocanales.

Características intrínsecas específicas. En general, de color naranja grisáceo (10YR 7/4). No se han encontrado datos cuantitativos sobre las características petrofísicas específicas de este tipo de marés.

Explotaciones tipo. Canteras de Bellver-Puig de sa Mesquita, canteras de sa Fontsanta de Sa Teulera (Palma); Torrenova, Cala Vinyes (costa de Calvià).
Estado explotación. Actualmente no existen explotaciones activas. Este tipo de marés se dejó de explotar posiblemente en la segunda mitad del siglo XIX.

Observaciones. Jovellanos (1806) indica que este tipo de marés fue el principal material utilizado en la construcción del Castillo de Bellver (Fig. 10D), extraído de las canteras existentes bajo el mismo castillo, y en el que también se utilizaron, en menor cuantía, marés de Portals (tipo $T_{2}$ ) y piedra de Santanyí (tipo M). El gran volumen de piedra extraído bajo el castillo y la longitud de algunas galerías, hace pensar que también sirvió para construir otros edificios de Palma, como la Catedral o la iglesia de la Santa Cruz. Los canteros solían marcar las piedras que manufacturaban, con un nombre o símbolo, a efectos de cobro de sus sueldos. Estos símbolos aún se pueden ver en muchas piezas del edificio del castillo de Bellver.

Fernández-Legido and Valero (2010) indican que en 1851, Jaime Conrado regaló bloques de marés para la reconstrucción de la fachada principal de la Catedral, que se había visto afectada por un movimiento sísmico (ver Bouvy, 1851,1953; Pujó, 1951). Dicho marés fue extraído de las canteras de sa Fontsanta, situadas en terrenos de saTeulera y Son Puigdorfila (Palma). EI 2 de abril de 1867, Mariano Conrado (hijo de Santiago) acordó con el obispado que regalaría el marés necesario para construir la iglesia de la Inmaculada Concepción (San Magín), extraído también de las canteras de la Fontsanta de SaTeulera.

Según el Archiduque Luis Salvador de Austria (Habsburgo-Lothringen, 1871), de las canteras de la Fontsanta de sa Teulera (Palma) se extrajo un marés muy parecido al de Bellver utilizado para construir las fachadas de la Catedral y de otras casas de Palma. 
Este tipo de arenisca se utilizó también para levantar el puente de la plaza de Sóller y las bóvedas de los dos puentes del ferrocarril en el Pont d'Inca. La explotación de esas canteras fue tan intensa que en ellas existían grandes corredores subterráneos, donde por orden municipal en el año 1870 fueron alojados gran número de personas afectadas por un brote de fiebre amarilla. En relación a las canteras de Castillo de Bellver, indica que probablemente fueron explotadas para la construcción del propio castillo y que a finales del siglo XIX ya mantenían las entradas clausuradas.

Recientemente Galiana (2009) ha proporcionado una visión detallada de las canteras y material extraído de las cuevas de Bellver. Por otra parte, Mas (2014) analiza la descripción hecha por Jovellanos de este tipo de marés y su contexto geológico.

Este tipo de marés se corresponde cronoestratigràficamente con la mayoría de marés explotado en la vecina isla de Menorca, correspondiente a la Unidad Inferior de Barras (Obrador and Pomar, 2004) o Unidad Intermedia (Rosell and Llompart, 2002) del Mioceno menorquín.

\section{Tipo S (calcilutitas y calcarenitas del Langhiense- Serravalliense)}

Concepto. Este tipo de marés, que corresponde a depósitos marinos carbonáticos del Mioceno medio, presenta dos subtipos bien diferenciados, el subtipo (a) correspondiente a un marés blanco flojo y pulverulento explotado antiguamente en Felanitx $y$ Manacor (Figs. 7, 10E,F), y el subtipo (b) correspondiente a niveles mucho más duros que todavía se explotan al S de la localidad de Felanitx (Fig. 8).

Denominación popular. Marés de Felanitx o marés de sa Mola (subtipo a). Actualmente, al subtipo (b), también se le denomina Piedra de Felanitx o marés brossenc (Fig. 8).

Unidad estratigráfica. Calizas de SonTalent (Pomar et al., 1983), que se corresponden con la Unidad Carbonática Serravalliense (Alvaro et al., 1984) y la Secuencia Carbonática de Manacor (TM. 2.1) (Simón and Ramón, 1986). Este sería el único tipo de marés de Mallorca afectado por la deformación alpina.

Edad. Mientras Alvaro et al. (1984) y Simón and Ramón (1986) sitúan estas formaciones en Serravallliense inferior, Pomar et al. (1983) las sitúan en una edad Langhiense superior-Serravalliense. Así pues tendría una edad cercana a los $14 \mathrm{Ma}$.

Distribución. Explotaciones de dimensiones reducidas en la zona de Felanitx y de la doble cubeta Manacor-Santa Sirga (Ver Anexo II y Fig. 11).
Litología. Calizas marinas bioclásticas, con un elevado contenido en fósiles. En relación a los niveles explotados existen dos litologías (subtipos): a) calcilutitas bioclásticas de textura wakestone-packstone con matriz blanca pulverulenta (Fig. 10F), grano de tamaño limo a arena fina mal seleccionado con pequeñas pasadas de cantos paleozoicos, mesozoicos y eocenos, así como cantos blandos de la unidad turbidítica subyacente (Formación Turbidítica de Banyalbufar, Rodríguez-Perea, 1984). Los cantos son de dimensiones centimétricas a subcentimétricas, y se encuentran flotando en la matriz preferentemente en los niveles inferiores de la unidad. Presentan porosidad intergranular e intragranular a favor de cámaras internas de bioclastos. Pueden presentar estructuras planares penetrativas (clivaje). b) Calcarenitas masivas duras con granos de tamaño grueso a muy grueso $(1 / 2-2,0 \mathrm{~mm})$ muy mal seleccionados y textura packstone-grainstone. El marés brossenc blanco (subtipo b), extraído de las capas más inferiores de la cantera de es Camp Roig (Felanitx) puede presentar cierta dolomitización $(0,4 \%$, Amengual and Sierra, 2008).

Paleontología. En ambos subtipos, los componentes bioclásticos son principalmente algas rodofíceas (Lithotamnium, Lithophyllum) que pueden formar rodolitos localmente muy abundantes y dispuestos en ciclos (Fig. 10E), foraminíferos (Amphistegina, Rotalia, Operculina, Heterostegina, Orbulina, Globigerinoides, etc.), briozoos, bivalvos (pectínidos, ostreidos), equinoideos y dientes de peces.

Ambiente sedimentario. Sedimentación carbonatada correspondiente a una plataforma marina depositada en una cuenca interna.

Características intrínsecas específicas. Este tipo de marés presenta dos texturas y durezas diferentes: el subtipo (a) correspondiente al marés de color blanco (N9), flojo, pulverulento y vaciadizo (Figs. 7, 10E,F) que se explotaba antiguamente en Felanitx (sa Mola) y Manacor (sa Real), y el subtipo (b) un marés bueno, muy duro y tupido (Fig. 8) que se extrae actualmente en Felanitx (es Camp Roig) con sus variedades blanca (en realidad color naranja muy pálido, 10YR 8/2) y roja (color rosa moderadamente anaranjado, 5YR 8/4). El subtipo (b) destaca por su elevada densidad, resistencia media y bajo coeficiente de absorción. Ver datos cuantitativos en el Anexo I.

Explotaciones tipo. Subtipo (a): sa Mola (Felanitx), sa Real, Son Jaume Andreu (Manacor); subtipo (b): es Camp Roig, sa Comerma (Felanitx).

Estado explotación. En la cantera activa de es Camp Roig (subtipo b) se extraen actualmente grandes bloques de un marés duro (Piedra de Felanitx o 


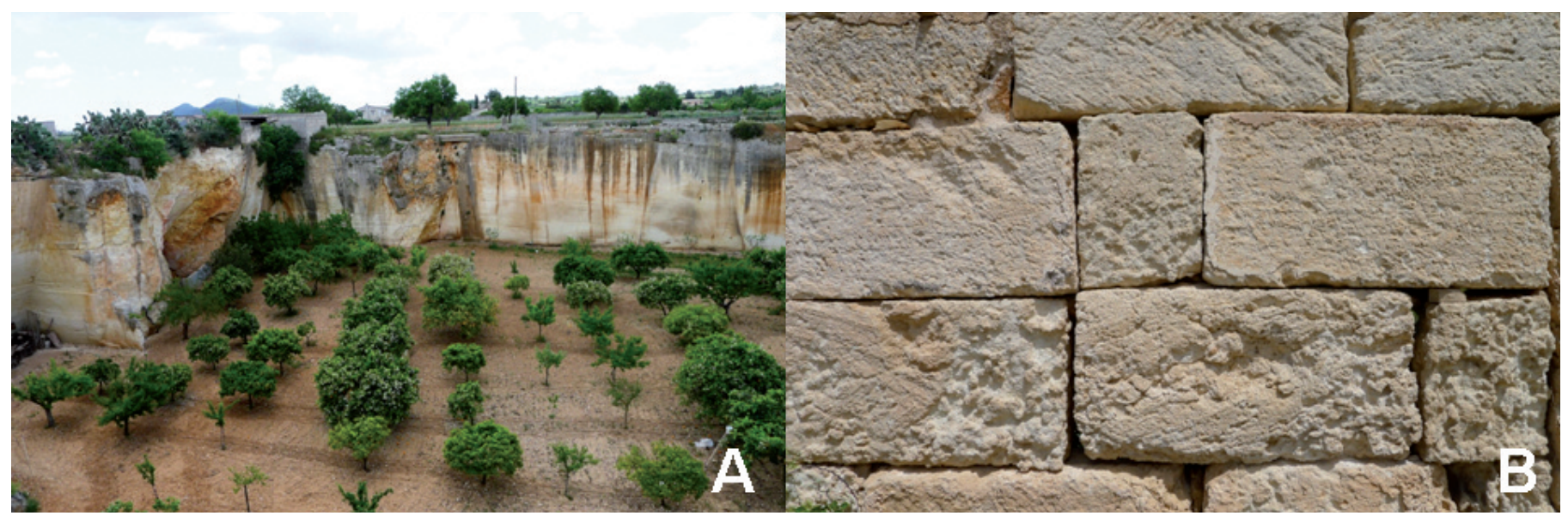

Figura 7. A) Cantera de Son Jaume Andreu (Manacor). B) Marés tipo S (subtipo a) de la misma cantera.

Figure 7. A) Overview of the Son Jaume Andreu quarry (Manacor). B) Mares type S (subtype a), from the same quarry.

marés brossenc) con las variedades roja y blanca (Fig. 8), destinadas básicamente a forros ornamentales y acabados. El subtipo (a) actualmente ya no se explota.

Observaciones. El Archiduque Luis Salvador (Habsburg-Lothringen, 1871) cita expresamente las canteras de sa Mola de Felanitx comparando su marés con el de Muro (tipo $T_{2}$ ). Se trata del marés de formación más antigua que se ha explotado en Mallorca.

\section{Conclusiones}

El marés de Mallorca, junto con las canteras de donde se extrae, además de constituir un valioso patrimonio histórico-etnológico-cultural, constituyen también un importante patrimonio geológico-natural que registra y nos permite seguir la evolución y la historia geológica de la isla durante los últimos 15 millones de años, desde el Mioceno medio (LanghienseSerravalliense) hasta el Pleistoceno.

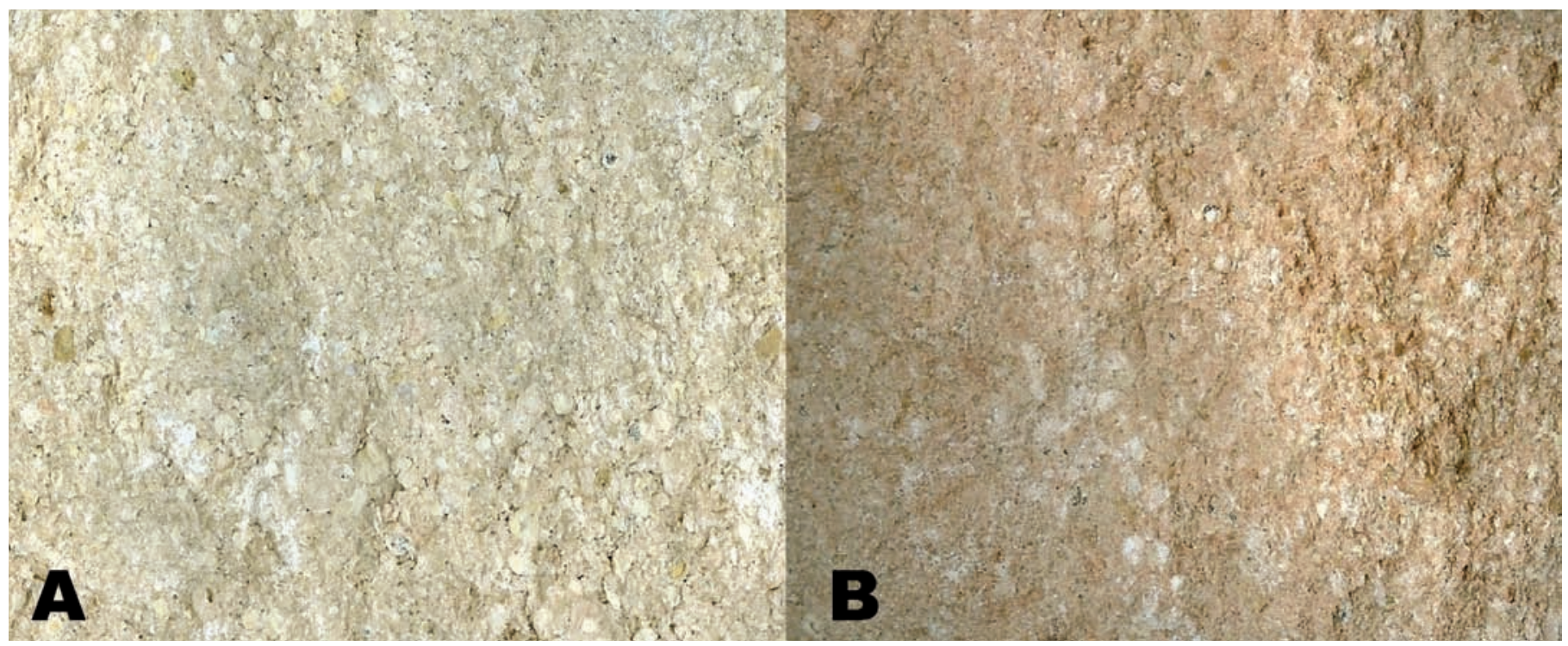

Figura 8. Marés tipo S (subtipo b) o Piedra de Felanitx en sus variedades blanca (A) y rojiza (B). La altura de las fotografías corresponde a $20 \mathrm{~mm}$.

Figure 8. Mares type $S$ (sub-type b) also denominated Piedra de Felanitx, in its whitish (A) and reddish (B) varieties. The height of the pictures corresponds to $20 \mathrm{~mm}$. 

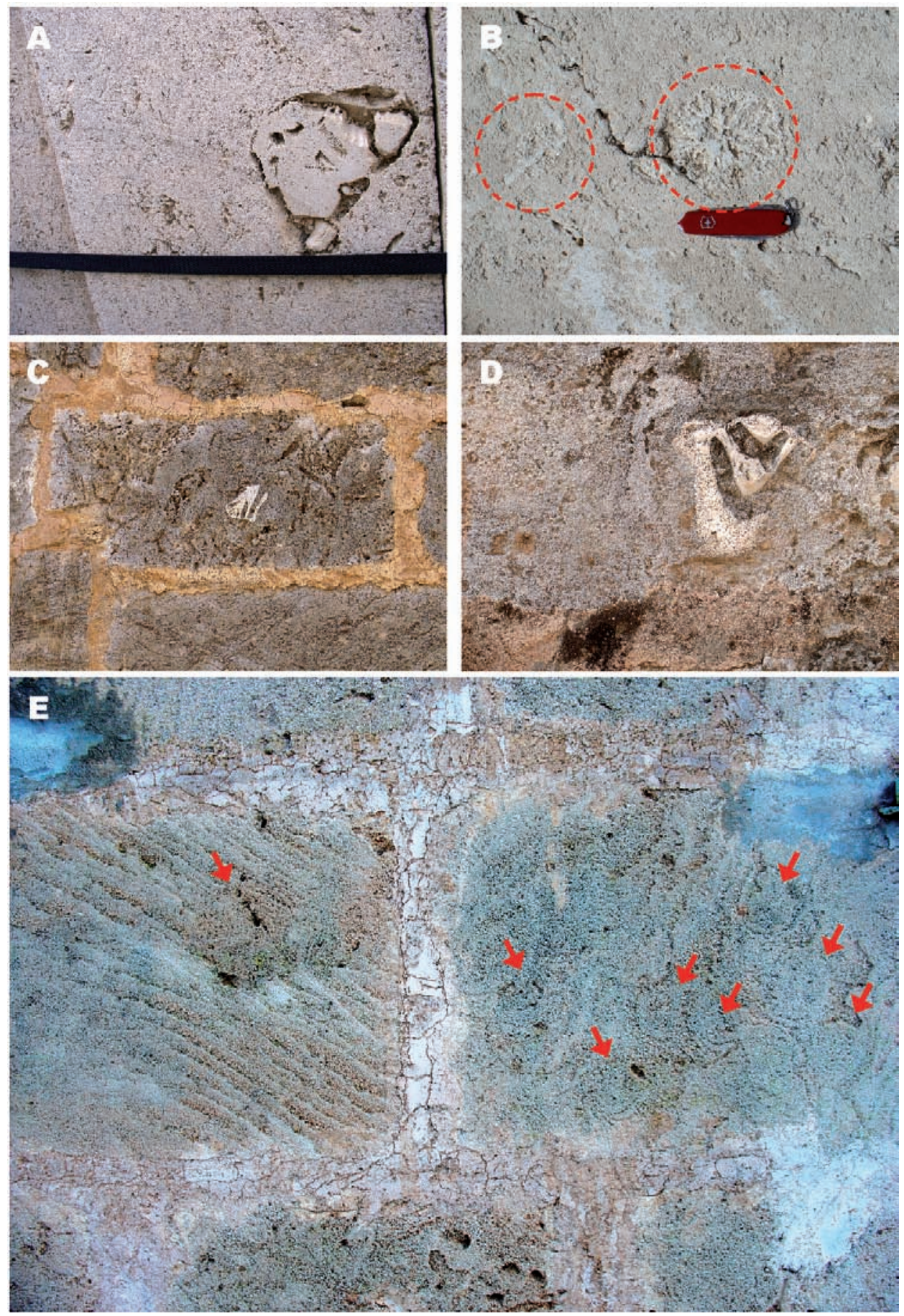

Figura 9. Fósiles característicos contenidos en diferentes litotipos de marés: A) Sección de un molde de un equinoideo detritívoro (Clypeaster sp.) en un sillar de marés tipo $\mathrm{T}_{2}$ de la cantera de Son Rafeló (Llucmajor); B) Secciones de rodolitos (algas rodofíceas) en un sillar de marés tipo $\mathrm{T}_{2}$ de la Cantera de Son Rafeló (Llucmajor); C) y D) Secciones del gasterópodo Strombus coronatus incluidos en los sillares de marés tipo $P_{2}$ (posiblemente de les playas pliocenas la zona de Son Mulet-Son Fullana (Llucmajor), formando parte del paramento exterior de una casa (esquina C/ Antoni Maura con C/ Antoni Garcies) de Llucmajor; E) Marés tipo $\mathrm{Q}$ de la zona de la Playa de Palma mostrando la característica laminación y bioturbación por icnitas (flechas) de Myotragus balearicus.

Figure 9. Characteristic fossils contained in different mares lothotypes: A) section of a cast of a detritivore echinoid (Clypeaster sp.) in a bloc of mares type $T_{2}$ from the Son Rafeló quarry (Llucmajor); B) sections of rhodolites (red algae) in a bloc of mares type $T_{2}$ from the Son Rafeló quarry (Llucmajor); C) and D) sections of the gastropod Strombus coronatus included in blocks of mares type P2, possibly from the Pliocene beaches of the zone of Son Mulet-Son Fullana (Llucmajor) that form part of the external face of a house on the corner of Antonio Maura and Antoni Garcies streets in Llucmajor village; E) mares type Q, from the quarries of the zone of Playa de Palma, showing its characteristic lamination and bioturbation by Myotragus balearicus ichnites (arrows). 

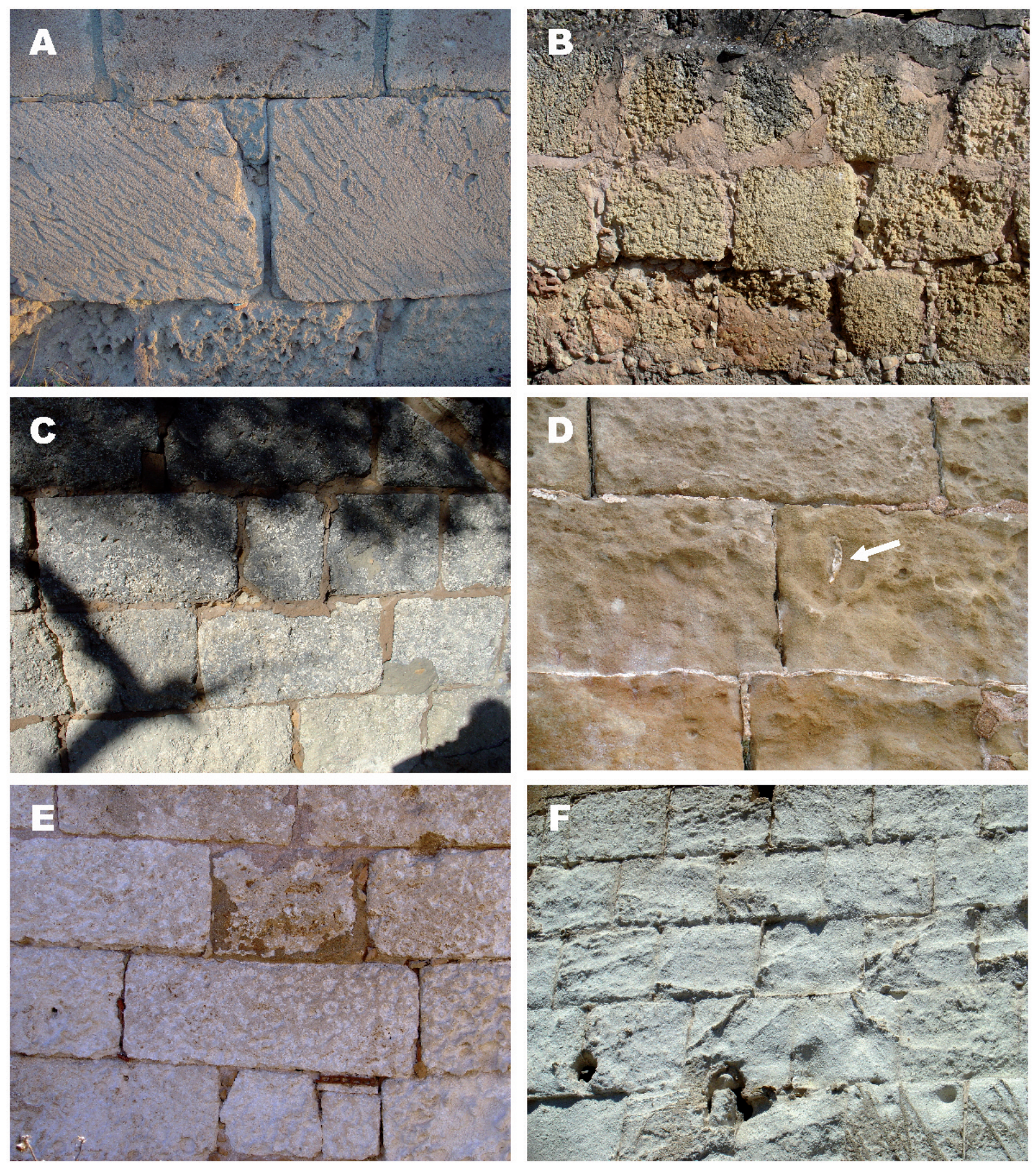

Figura 10. Diferentes litotipos de marés actualmente en desuso: A) Marés tipo $Q$, de las canteras de la Playa de Palma, con sus laminaciones características; $B$ ) Marés tipo $P_{1}$, de la zona de Sta. Eugènia, de color amarillo y baja calidad; $C$ ) Marés tipo $T_{2}$, de la antigua cantera de la Cueva de la Mare de Deu (Portals Vells, Calvià), de aspecto granulado con infinidad de fragmentos de algas; D) Marés tipo T, de los paramentos exteriores de la muralla del Castell de Bellver (Palma), con secciones y fragmentos del equinoideo aplanado Amphiope bioculata (flecha blanca); E) Marés tipo S (subtipo a), de la pedrera de sa Real (Manacor), con gran cantidad de rodolitos algales característicos; F) Marés tipo S (subtipo a), de las canteras de sa Mola (Felanitx), con su aspecto característico pulverulento y vaciadizo (buidadís).

Figure 10. Different lithotypes of mares currently in disuse: A) mares type $Q$, from the quarries of the zone of Playa de Palma, with its characteristic laminations; $B$ ) mares type $P_{1}$, from the zone of Sta. Eugènia, of a yellow colour and low quality; $C$ ) mares type $T_{2}$, from the old quarry of the Mare de Deu cave (Portals Vells, Calvia), of a granular aspect with abundant algal fragments; D)mares type T1, of the exterior faces of the walls of Bellver Castle (Palma), with sections and fragments of flat echinoid Amphiope bioculata (white arrow); E) mares type $S$ (subtype b), from the sa Real quarry (Manacor); F) mares type S (subtype a), from sa Mola quarry (Felanitx), with a characteristic dusty, hollow aspect. 
El concepto de marés viene definido tanto por las características intrínsecas del propio material como por el tratamiento y uso que se puede hacer del mismo. El marés como término debe referirse a una calcarenita, de fácil trabajar y usada como material de construcción, abundante en la isla de Mallorca.

El marés de Mallorca es una roca sedimentaria caliza de naturaleza clástica, de origen marino o dunar, más o menos consolidada, constituida por más del $50 \%$ de elementos carbonáticos (bioclastos, litoclastos, etc.), pertenecientes a la fracción arena, con granos comprendidos entre 2 y $1 / 16 \mathrm{~mm}$ de grosor aglutinados por cemento. Se trata de un material constituido principalmente por carbonato cálcico, con una alta porosidad, en general muy blando y de una resistencia a la compresión muy baja en comparación a otras piedras utilizadas como materiales de construcción.

La cronoestratigrafía del marés de Mallorca incluye desde el Langhiense-Serravalliense ( 14 millones de años) hasta el Pleistoceno superior ( 20.000 años) (Fig. 1).

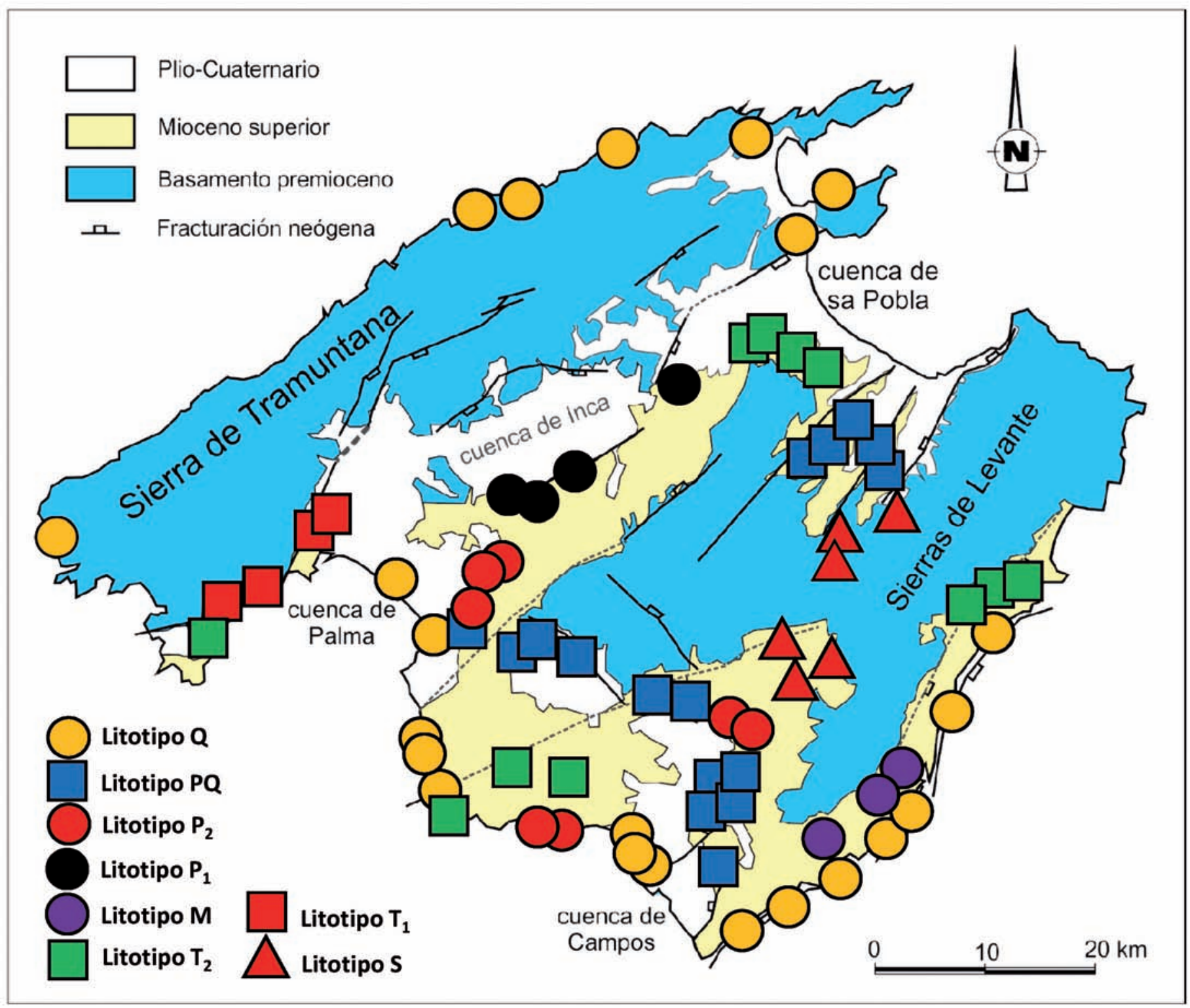

Figura 11. Distribución geográfica de las explotaciones de los diferentes litotipos de marés sobre el mapa geoestructural (Fornós and Gelabert, 2004) de la isla de Mallorca.

Figure 11. Geographical distribution of the quarries of different lithotypes of mares on a geostructural map (Fornós and Gelabert, 2004) of the island of Mallorca. 
En la isla de Mallorca, se han podido identificar hasta 8 litotipos de marés (Tabla 1), de los cuales los 2 de formación más moderna (tipo $\mathrm{Q}$ y $\mathrm{PQ}$ ) son de origen eólico mientras que los 5 restantes son de origen marino. De estos 8 litotipos, $3\left(\mathrm{Q}, \mathrm{P}_{1} \mathrm{y}_{\mathrm{1}}\right)$ ya no se explotan ni utilizan en la actualidad.

En general, todos los litotipos de marés de Mallorca deben ser considerados como calizas de muy baja dureza ("blandas o muy blandas": Da: 1,2$1,8 \mathrm{~g} / \mathrm{cm}^{3}$, media: $1,73 \mathrm{~g} / \mathrm{cm}^{3}$ y $\left.\mathrm{Rc}<120 \mathrm{~kg} / \mathrm{cm}^{2}\right)$. Tan sólo el marés de tipo $\mathrm{S}$, subtipo b (brossenc de Felanitx), tipo M (piedra de Santanyí) y algunos del tipo $T_{2}$ (Muro, Cas Busso) se pueden considerar calizas de dureza intermedia (Da: 1,80-2,20 g/ $\mathrm{cm}^{3}, \mathrm{Rc}$ $>250 \mathrm{~kg} / \mathrm{cm}^{2}$.

La variabilidad en las características intrínsecas (porosidad, densidad, cementación, etc.) y la irregularidad de respuesta (absorción, resistencia, etc.) hacen que el marés sea un material de difícil homologación y estandarización (Ver Anexo I).

En la restauración de edificios, en relación a sustitución de piezas de marés, se precisa conservar el tipo original para no desvirtuar las características patrimoniales genuinas, siendo por tanto necesario que a tal efecto se tengan en cuenta la geocronología y características intrínsecas de los diferentes litotipos descritos en este trabajo.

\section{Agradecimientos}

A Toni Riera de la empresa Trossos de Marès, SL (Petra), Miquel Ramis de las canteras Can Ramis SL (s'Aranjassa) y Miquel Nicolau de la cantera de sa Sínia Nova (Manacor), por su magnífica disponibilidad. A Macià Catany y Tomeu Juliá, de sa Caseta, de Campos, por su paciencia y explicaciones.

A Joan Arbona Mas, por las referencias proporcionadas sobre antiguas explotaciones de marés ubicadas en el litoral de la Sierra de Tramuntana.

Agradecer las correcciones y sugerencias realizadas por dos revisores anónimos que han contribuido notablemente a mejorar la calidad del presente trabajo.

El presente trabajo constituye parte de un trabajo de investigación predoctoral realizado, bajo la supervisión del Dr. Joan J. Fornos Astó, dentro del programa de doctorado del Departamento de Ciencias de la Tierra de la Universidad de las Islas Baleares.

\section{Referencias}

Alcover, A.M.; Moll, F.B. 1951-1968. Diccionari CatalàValencià-Balear. Ed. Moll. 10 vols. Palma de Mallorca.
Alomar, G. 2009. Lectura paisajística de las canteras de marès de Mallorca. In: Pillet, F., Cañizares, M. C., Ruiz, A.R. (coords.): Geografía, territorio y paisaje: el estado de la cuestión. Actas del XXI Congreso de Geógrafos Españoles, Ciudad Real 27-29 de octubre de 2009, pp 761-773.

Alonso, F.J., Ordaz, J. and Esbert, R.M. 1996. Deterioro selectivo de la piedra de construcción de la catedral de Palma de Mallorca. Geogaceta, 20 (5): 1228-1231.

Alvaro, M., Barnolas, A., Del Olmo, P., Ramírez del Pozo, J. and Simó, A. 1984. El Neógeno de Mallorca: Caracterización sedimentológica y bioestratigráfica. Boletín Geológico y Minero, 95(1): 3-25.

Amengual, C. and Serra, M.M. 2008. El marés y la piedra de Santanyí en Mallorca: Canteras y caracterización básica. Proyecto de final de carrera. ArquitecturaTècnica. Escola Politècnica Superior. Universitat de les Illes Balears. 560 pp.

Barba, R. (ed.). 1999. Paisatge de les pedreres de Menorca. Restauració $i$ intervencions. Projectes del taller $\mathrm{V}$ del Master d'Arquitectura del Paisatge, Universitat Politècnica de Catalunya. 187 pp.

Barnolas, A. (coord.). 1991. Mapa Geológico de España. Escala 1:50:000. Hojas 643-645, 670-672, 697-700, 722b$725,748-749$. Segunda sèrie-Primera edición. Instituto Tecnológico Geominero de España (ITGE). Madrid.

Bizon, G., Bizon, J.J., Bourrouilh, R. and Massa, D. 1973. Présence aux îles Baléares (Méditerranée Occidentale) de sédiments "messiniens" déposses dans une mer ouverte á salinité normale. Comptes Rendus de l'Académie des Sciences, Série D, 277 (12): 985-988.

Bourillot, R., Vennin, E., Rouchy, J.M., Blanc-Valleron, M.M., Caruso, A. and Durlet, C. 2010. The end of the Messinian Crisis in the western Mediterranean: Insights from the carbonate platforms of south-eastern Spain. Sedimentary Geology, 229: 224-253.

Bouvy, P. 1851. Sobre el Terremoto ocurrido en la Isla de Mallorca el 15 de mayo último. Revista Minera, 2(26): 375-378.

Bouvy, P. 1853. Notice sur le tremblement de terre du 15 mai 1851, de l'île de Majorque. Bulletin de la Société géologique de France, 10: 359-364.

Butzer, K.W. 1975. Pleistocene littoral sedimentary cycles of the Mediterranean Bassin: A Malloquin view. In: Butzer K.W. and Isaac, G. (eds.) After the Australopithecines. The Hague, 25-71.

Clemmensen, L.B., Lisborg, T., Fornós, J.J. and Bromley, R.G. 2001. Cliff-front aeolian and colluvial deposits, Mallorca, Western Mediterranean. Terra Nova, 9: 251254.

Colom, G. 1975. Geologia de Mallorca. Diput. Prov. Bal. Inst. Estudios Baleáricos. Patronato "J. Mª Quadrado". CSIC. 2 vols. Palma de Mallorca. 519 pp.

Colom, G. 1980. Nota preliminar sobre la existencia del plioceno inferior, marino, en Mallorca (Baleares). Acta Geológica Hispánica, 15(2): 45-49.

Colom, G. 1985. Estratigrafía y Paleontología del Andaluciense y del Plioceno de Mallorca (Baleares). Boletín Geológico y Minero, 96(3): 235-302.

Colom, G., Sacares, J. and Cuerda, J. 1968. Las formaciones 
marinas y dunares pliocénicas de la región de Llucmajor (Mallorca). Bolletí de la Societat d'Història Natural de Balears, 14: 46-61.

Cornée, J.J., Saint Martin, J.P., Conesa, G., Münch, P., André, J.P., Saint Martin, S. and Roger, S. 2004. Correlations and sequence stratigraphic model for Messinian carbonate platforms of the western and central Mediterranean. International Journal of Earth Sciences, 93: 621-633.

Cuerda. J. 1975. Los tiempos Cuaternarios en Baleares. Conselleria de Cultura, Educació i Esports del Govern Balear. 2a edició (1989). Palma de Mallorca. 310 pp.

Cuerda. J., Sacarés, J., Colom, G. 1969. Hallazgo de terrenos pliocenos, marinos, en la región de Llucmayor (Mallorca). Acta Geológica. Hispánica., 4(2): 35-37.

Cuerda, J., Antich, S. and Soler, A. 1982. La secuencia pleistocénica dunar de Son Moson (Mallorca) y sus correlaciones faunísticas y estratigráficas Bolletí de la Societat d'Història Natural de Balears, 26: 13-35.

De Gibert, J.M., Mas, G. and Ekdale, A.A. 2012. Architectural complexity of marine crustacean burrows: unusual helical trace fossils from the Miocene of Mallorca, Spain. Lethaia, 45: 574-585.

Fernández-Legido, R. and Valero, G. 2010. Possessions de Palma. Història i arquitectura del terme de la ciutat. http://possessionsdepalma.net

Florit, F. and Sauleau, L. 1995. Pedreres de marès. Lhítica i Sa Nostra, Caixa de Balears. Barcelona. 135 p.

Fornós, J.J. 1983. Estudi sedimentològic del Miocè terminal a I'illa de Mallorca. Tesi de Llicenciatura. Universitat de Barcelona. 228 pp.

Fornós, J.J. and Gelabert, B. 2004. Baleares. In: Vera, J.A. (Ed.) Geologia de España. SGE-IGME. pp 450-464.

Fornós, J.J. and Pomar, L. 1983. Mioceno superior de Mallorca: Unidad calizas de Santanyí ("Complejo terminal"). In: Pomar, L., Obrador, J., Fornós, J.J. and Rodríguez-Perea, A. (eds.), El Terciario de las Baleares (Mallorca - Menorca). Guía de las excursiones. X Congreso Nacional de Sedimentología, Menorca 1983. Grupo Español de Sedimentología. Palma de Mallorca, 177-206.

Fornós, J.J., Marzo, M., Pomar, L., Ramos-Guerrero, E., and Rodríguez-Perea, A. 1991. Evolución tectono-sedimentaria y anàlisis estratigràfico del Terciario de la Isla de Mallorca. I Congreso del Grupo Español del Terciario. Libro-Guía Excursión n 2. Ed. F. Colombo. Vic. 145 pp.

Fornós, J.J., Bromley, R.G., Clemmensen, L.B. and Rodríguez-Perea, A. 2002. Tracks and trackways of Myotragus balearicus Bate (Artiodactyla, Caprinae) in Pleistocene aeolianites from Mallorca (Balearic Islands, Western Mediterranean). Palaeogeography, Palaeoclimatology, Palaeoecology, 180: 277-313.

Fornós, J.J., Rodríguez-Perea, A., Bromley, R.G. and Clemmensen, L.B. 2007. S'Estret des Temps: Registro quaternario, eolianitas y estructuras asociadas. In: Fornós, J.J., Ginés, J. and Gómez-Pujol, L. (eds.): Geomorfologia Litoral: Llevant y Migjorn de Mallorca. Monografies de la Societat d'Història Natural de les Balears, 15: 173-184.

Fullana, M. 1974. Diccionari de l'art i dels oficis de la construcció. Ed. Moll. 8à edició (gener, 2005). Palma. 490 pp.
Galiana, P. 2009. Les coves de Bellver. Regidoria de Cultura, Patrimoni i Política Lingüística. Ajuntament de Palma. Col-lecció Castell de Bellver, 1. Palma, 191 pp.

Galván-Llopis, V. and Ferrer-Graciá, M.J. 1997. La piedra del marés: un material humano. Servicio de Publicaciones de la Universidad de Navarra-MEC-IGME. Revista de Edificació, 26: 54-57.

Garcia-Inyesta, N. and Oliver, G. 1997. Construir en Marès. Col-legi Oficial d'Arquitectes de Balears. 270 pp.

Gibert, J. 1997. La piedra natural en Baleares. Revista Roc Máquina, Noviembre, 1997: 84-85.

González-Hernández, F.M., Goy, J.L., Zazo, C. and Silva, P.G. 2001. Actividad eólica-cambios del nivel del mar durante los últimos 170.000 años (Litoral de Mallorca, Islas Baleares). Cuaternario y Geomorfología, 15 (3-4): 67-75.

Habsburg-Lothringen, L.S. 1871. Die Balearen in Wort und Bild geschildert. Zweiter Band. Die eigentlichen Balearen. Drittes Buch. Mallorca. I. Allgemeiner theil. F.V. Brockhaus. 665 pp. Leipzig. Traducción al castellano: Habsburg-Lothringen, L.S. 1989. Las Baleares por la palabra y el grabado. Las Baleares propiamente dichas. Mallorca (parte general). Traducción del vol. III de la segunda parte de Die Balearen. Edición Caja de Baleares "Sa Nostra", vol 6, 931 pp.

Institut d'Estudis Catalans. 1995. Diccionari de la Ilengua catalana. Edicions 3 i 4. Edicions 62 - Ed. Moll Enciclopèdia Catalana - Publicacions de I'Abadia del Montserrat. Barcelona-Palma de Mallorca-València. 1908 pp.

Jovellanos, G.M. 1806. Memorias del Castillo de Bellver. In: Muntaner LI. (ed.). 1999. Gaspar Melchor de Jovellanos. Obras Mallorquinas. L'Espill, 3: 56-100.

Mas, G. 2000. Ictiofauna del Pliocè mitja-superior de la conca sedimentària de Palma (IIles Balears, Mediterrània Occidental). Implicacions paleoambientals. Bolletí de la Societat d'Història Natural de Balears, 43: 39-61.

Mas, G. 2004. Comunicació preliminar sobre la freqüencia de grans Cetacis (Mammalia) al Pliocè mitjà-superior de la conca sedimentària de Palma (Illes Balears). Implicacions paleoambientals. In: Pons, G.X. (edit.), IV Jornades de Medi Ambient de les Illes Balears. Ponències i Resums. Societat d'Història Natural de Balears. pp 63-67.

Mas, G. 2011a. La pedrera des Monjos: 4 milions d'anys d'història geològica de Mallorca i la Mediterrània. De la crisi de salinitat messiniana a les platges i dunes del Pliocè-Quaternari. Actes de les III Jornades d'Estudis Locals de Porreres, 2010. Col-lecció Patrimoni de Porreres, 12. Ajuntament de Porreres. pp 51-60.

Mas, G. 2011b. El marès de Mallorca: concepte, caracterització i tipologia. Estudis Baleàrics, 100/101: 151-171.

Mas, G. 2013. Primera cita d'icnofòssils atribuïbles a formigues (Hymenoptera, Formicidae) a paleosòls del Plistocè de Mallorca. In: Pons, G.X., Ginard, A. i Vicens, D. (eds.) VI Jornades de Medi Ambient de les IIles Balears. Ponències i Resums. Soc. Hist. Nat. Balears. pp 56-58.

Mas, G. 2014. Jovellanos i la geologia de Bellver. Primera descripció geològica documentada a I'illa de Mallorca. 
Bolletí de la Societat d'Història Natural de Balears, 57 (a prensa).

Mas, G. and Ripoll, J. 2010. Cambres de pupació d'insectes coleòpters del Pliocè-Pleistocè inferior de Mallorca (Illes Balears, Mediterrània occidental). Significació paleoambiental i cronoestratigràfica. Bolletí de la Societat d'Història Natural de Balears, 53: 91-106.

Mas, G., Fornós, J.J. and López, B. 2013. Revisió de la sèrie neògena de la zona de cala Pi-Vallgornera-es Pas (Llucmajor, Mallorca). In: Pons, G.X., Ginard, A. and Vicens, D. (eds.), VI Jornades de Medi Ambient de les Illes Balears. Ponències i Resums. Societat d'Història Natural de Balears, 114-116.

Mas, G., Gelabert, B., Fornós, J.J. 2014. Evidencias de desplazamiento direccional de la falla de Sencelles (Mallorca, Islas Baleares). In: J.A. Álvarez-Gómez \& F. Martín González (Eds.): Una aproximación multidisciplinar al estudio de las fallas activas, los terremotos y el riesgo sísmico. Segunda reunión ibérica sobre fallas activas y paleosismología, Lorca (Murcia, España). pp. 47-50.

Mateos, R.M., Durán, J.J. and Robledo, P.A. 2011. Mares Quarries on the Majorcan Coast (Spain) as Geological Heritage Sites. Geoheritage, 3: 41-54.

Mingarro, F., Fort, R. and López-Azcona, M.C. 1992. Análisis de la degradación del Ilustre Colegio Notarial de Palma de Mallorca, España, para su restauración. Congreso internacional Rehabilitación del patrimonio arquitectónico y edificación. Canarias, 13-18 Julio. Ponencias tomo 1, 148-152.

Moreno, C. and Muñoz, R. 1988. El marés; su arquitectura, patologia y utilización en Menorca. XXII Premio Ateneo de Mahón 1983. Revista de Menorca, any LXXIX, 7a època, $1 \mathrm{r}$ trimestre 1988: 5-30.

Morey, B. 2009. Santa Eugènia. Natura i medi. Geologia i botànica. Ajuntament de Santa Eugènia. Santa Eugènia. $280 \mathrm{pp}$.

Morey, B. and Mas, G. 2009. Aproximació al Neògen de Santa Eugènia (Mallorca, Illes Balears, Mediterrània occidental). Bolletí de la Societat d'Història Natural de Balears, 52: 99-122.

Muntaner, A. 1959. Noticia sobre la existencia de una cantera de epoca romana en las inmediaciones de Cala-Pi (Mallorca). Bolletí de la Societat d'Història Natural de les Balears, 5: 60-61.

Obrador, A. and Pomar, L. 2004. El Miocè del Migjorn. In: Fornós, J., Obrador, A. and Rosselló, V.M. (eds.) Història natural del migjorn de Menorca. El medi físic i I'influx humà. Mon. Societat d'Història Natural de les Balears, 11: 73-92.

Pomar, L., Marzo, M. and Barón, A. 1983. El Terciario de Mallorca. In: Pomar, L., Obrador, J., Fornós, J.J. and Rodríguez-Perea, A. (eds.) El Terciario de las Baleares (Mallorca-Menorca). Guía de las excursiones. $X$
Congreso Nacional de Sedimentología, Menorca 1983. Grupo Español de Sedimentología. pp. 21-44.

Pomar, L., Rodriguez-Perea, A., Sabat, F. and Fornós, J. 1990. Neogene stratigraphv of Mallorca Island. Iberian Neogene Basins (IXth Congress R.C.M.N.S.). Paleontologia i Evolució, Mem. Esp., 2: 269-320.

Pomar, L., Ward, W.C. and Green, D.G. 1996. Upper Miocene Reef Complex of the Llucmajor area, Mallorca, Spain. In: Franseen, E., Esteban, M., Ward, W.C. and Rouchy, J.M. (eds.) Models for Carbonate Stratigraphy from Miocene Reef Complexes of the Mediterranean regions. SEPM Concepts in Sedimentology and Paleontology Series, 5: 191-225.

Pujó, M. 1851. Le tremblement de terre du 15 mai 1851 de l'île de Majorque. Comptes Rendus de l'Académie des Sciences, 2: 23.

Pons, M. 2002. El marès. Característiques i tractaments. In: Pons, L. (ed.): De pedra. Centre d'Estudis Locals d'Alaior, pp. 143-158.

Ramis, M. 2013. Artifex Balear. http://www.artifexbalear.org

Riba, O. (coord.) 1997. Diccionari de Geologia. Institut d'Estudis Catalans - Enciclopèdia Catalana. Barcelona. $1407 \mathrm{pp}$.

Rodríguez-Perea, A. 1984. El Mioceno de la Serra Nord de Mallorca. Estratigrafía, sedimentología e implicaciones estructurales. Tesi doctoral. Universitat de BarcelonaUniversitat Palma de Mallorca. 532 pp.

Rosell, J. and Llompart, C. 2002. El naixement d'una illa. Menorca. Guia de geologia pràctica. Impressió i relligat Dacs, Indústria Gràfica, S.A. Moncada i Reixac. 279 pp.

Rosselló, V.M. 1964. Mallorca: El Sur y Sureste. Municipios de Llucmajor, Campos, ses Salines, Santanyí, Felanitx y Manacor. Cámara Oficial de Comercio, Industria y Navegación de Mallorca. Palma de Mallorca. 553 pp.

Rosselló, V.M. 1971. Plioceno marino en el Migjorn de la Isla de Mallorca. Estudios Geográficos, 123: 373-376.

Salvà, C. 2012. Fissures on the landscape: the sandstone quarries, traces of the heritage landscape of Mallorca. ARA Journal of Tourism Research, 3(2): 117-124.

Salvà, C. 2013. La memoria de un paisaje grabado. Las canteras de marès, trazas territoriales de un nuevo paisaje de Mallorca. Labor \& Engenho, 7(3): 7-26.

Sánchez-Cuenca, R. 2010. El marés. El material, su origen, historia, propiedades, canteras y calidades disponibles actualmente. Ramón Sánchez-Cuenca (ed.). 124 pp.

Simó, A. and Ramón, X. 1986. Análisis sedimentológico y descripción de las secuencias deposicionales del Neógeno postorogénico de Mallorca. Boletín. Geológico y Minero, 97(4): 445-472.

Vich, F. 2006. Trencadors dels segles XIX i XX. Ajuntament de Llucmajor. 106 pp.

Vilafranca, J. 2009. Diagnóstico e intervención sobre construcciones históricas: rehabilitación de edificios construidos en piedra de "marés" en la Isla de Menorca. Tesis Doctoral. UNED. 
Mas Gornals, G., 2017. Hacia una tipología de la piedra de marés de Mallorca. Concepto... Boletín Geológico y Minero, 128 (2): $301-328$

ANEXO I

\begin{tabular}{|c|c|c|c|c|c|c|c|c|c|c|c|c|c|c|c|c|c|}
\hline Litotipo & Cantera & Municipio & $\mathrm{Da}$ & Po & $\mathbf{P}$ & $\mathrm{Ca}$ & Rc & $\mathbf{R i}$ & Rf & Sol & Res & Rerist & Cal & Cua & Dol & Observaciones & Fuente \\
\hline M & Santanyi indet. & Santanyí & 1,79 & & & 3,48 & 131 & & 55 & & & & & & & & 2 \\
\hline M & Santanyi indet. & Santanyí & 1,76 & & & & 231 & & & & & & & & & & 1 \\
\hline M & Son Jorda & Santanyí & 1,80 & 6,6 & 33,6 & 5,20 & & & & & & & 100,0 & & & & 3 \\
\hline \multicolumn{2}{|c|}{ Media litotipo M } & & 1,78 & 6,6 & 33,6 & 4,34 & 181 & & 55 & & & & & & & & \\
\hline P2 & Can Casetes & Llucmajor & 1,36 & 45,8 & 52,1 & 26,95 & 30 & 70 & & 3,4 & $\mathrm{C}+\mathrm{A}$ & 7 & & & & & 4 \\
\hline $\mathrm{P} 2$ & Son Garau & Campos & 1,61 & 36,8 & 42,9 & 17,01 & 69 & 70 & & 9,1 & $\mathrm{C}$ & 13 & & & & & 4 \\
\hline \multicolumn{2}{|c|}{ Media litotipo P2 } & & 1,61 & 35,5 & 42,5 & 18,35 & 45 & 70 & 21 & 6,3 & & 10 & & & & & \\
\hline $\mathrm{PQ}$ & Arenal indet. & Palma & 1,46 & & & 23,19 & 35 & & 18 & & & & & & & & 2 \\
\hline $\mathrm{PO}$ & Can Bon Jesús & Petra & 1,46 & 38,8 & 47,3 & 21,44 & 33 & & & 2,0 & $\mathrm{C}$ & 17 & & & & & 4 \\
\hline $\mathrm{PQ}$ & Can Bon Jesús & Petra & 1,76 & 29,1 & 40,1 & 11,49 & 83 & & & & & 5 & & & & & 4 \\
\hline $\mathrm{PQ}$ & Can Casetes & Llucmajor & 1,64 & 34,1 & 40,0 & 15,48 & 118 & 115 & & 1,7 & C & 13 & & & & & 4 \\
\hline $\mathrm{PO}$ & Cas Villafranquer & Petra & 1,74 & 31,7 & 36,3 & 13,30 & & & & & & & 99,2 & 0,8 & & & 3 \\
\hline $\mathrm{PO}$ & Galdent & Llucmajor & 1,58 & 34,4 & 42,9 & 15,64 & 52 & 150 & & 3,7 & $\mathrm{C}+\mathrm{A}$ & 37 & & & & & 4 \\
\hline $\mathrm{PQ}$ & Galdent & Llucmajor & 1,66 & 33.1 & 41,1 & 15,80 & & & & & & & 97,0 & 3,0 & & & 3 \\
\hline $\mathrm{PQ}$ & Mayol II & Petra & 1,51 & 35,9 & 43,1 & 20,63 & 43 & 60 & & 1,3 & $\mathrm{C}$ & 13 & & & & & 4 \\
\hline $\mathrm{PO}$ & Sa Cabana & Llucmajor & 1,69 & 30,1 & 38,8 & 13,90 & 85 & 55 & & 4,7 & $\mathrm{C}+\mathrm{A}$ & 13 & & & & & 4 \\
\hline $\mathrm{PQ}$ & Sa Murtera & Manacor & 1,37 & 39,3 & 52,8 & 22,25 & 17 & 20 & & 3,1 & $A+C$ & 6 & & & & & 4 \\
\hline PO & Sa Sinia Nova & Manacor & 2,24 & 13,6 & 20,8 & 0,86 & 427 & 130 & & 0,8 & $A+C$ & 27 & & & & $\begin{array}{c}\text { fuerte } \\
\text { recristalización }\end{array}$ & 4 \\
\hline PO & Sa Sinia Nova & Manacor & 2,07 & 18,2 & 26,2 & 4,30 & 290 & 150 & & 3,2 & $A+C$ & 11 & & & & $\begin{array}{c}\text { fuerte } \\
\text { recristalización }\end{array}$ & 4 \\
\hline S & Es Camp Roig & Felanitx & 1,96 & & & 9,23 & 59 & & 54 & & & & & & & Subtipo b & 2 \\
\hline$S$ & Es Camp Roig & Felanitx & 2,20 & 15,9 & 19,4 & 9,70 & & & & & & & 99,6 & & 0,4 & Subtipo b - blanco & 3 \\
\hline$S$ & Es Camp Roig & Felanitx & 2,04 & 21,8 & 24,6 & 8,10 & & & & & & & 98,6 & 1,4 & & Subtipo b - rojizo & 3 \\
\hline \multicolumn{2}{|c|}{ Media litotipo S } & & 2,00 & 22,3 & 26,8 & 8,80 & 125 & 115 & 54 & 3,6 & & 9 & & & & & \\
\hline T2 & Cas Busso & Llucmajor & 1,32 & 45,1 & 52,9 & 26,37 & 34 & 70 & & 0,3 & $A$ & 4 & & & & & 4 \\
\hline T2 & Cas Busso & Llucmajor & 2,13 & 16,6 & 23,5 & 1,16 & 592 & 110 & & 0,5 & $\mathrm{C}+\mathrm{A}$ & 17 & & & & & 4 \\
\hline $\mathrm{T} 2$ & Muro indet. & Muro & 1,53 & & & 23,62 & 44 & & 23 & & & & & & & & 2 \\
\hline $\mathrm{T} 2$ & Sa Taulada & Sta. Margalida & 2,16 & 18,9 & 22,9 & 6,10 & 473 & & & & & 17 & & & & & 4 \\
\hline $\mathrm{T} 2$ & Sa Taulada & Sta. Margalida & 1,88 & 27,7 & 33,1 & 3,37 & 328 & & & 0,3 & $A+C$ & 27 & & & & & 4 \\
\hline $\mathrm{T} 2$ & Son Auba & Muro & 1,65 & 37,7 & 41,2 & 11,65 & 122 & 115 & & 0,8 & $A$ & 17 & & & & & 4 \\
\hline $\mathrm{T} 2$ & Son Auba & Muro & 2,22 & 10,2 & 20,6 & 0,58 & 530 & & & 0,2 & $A$ & 37 & & & & & 4 \\
\hline $\mathrm{T} 2$ & Son Auba & Muro & 1,64 & 38,6 & 42,1 & 17,00 & & & & & & & 47,9 & & 52,9 & & 3 \\
\hline $\mathrm{T} 2$ & Son Rafeló & Llucmajor & 1,67 & 33,1 & 40,2 & 5,42 & 185 & 115 & & 0,3 & A & 35 & & & & & 4 \\
\hline T2 & Sta. Bàrbara & Manacor & 1,80 & 29,0 & 35,5 & 3,51 & 130 & 75 & & 0,8 & $A+C$ & 13 & & & & & 4 \\
\hline $\mathrm{T} 2$ & Vernissa Vell & Sta. Margalida & 1,71 & 32,9 & 38,5 & 3,01 & 171 & 80 & & 0,3 & $A$ & 20 & & & & & 4 \\
\hline \multicolumn{2}{|c|}{ Media litotipo T2 } & & 1,79 & 29,0 & 35,1 & 9,25 & 261 & 94 & 23 & 0,4 & & 21 & & & & & \\
\hline \multicolumn{2}{|c|}{ Media general } & & 1,73 & 29,6 & 37,1 & 12,93 & 146 & 91 & 34 & 2,5 & & 16 & & & & & \\
\hline
\end{tabular}


Mas Gornals, G., 2017. Hacia una tipología de la piedra de marés de Mallorca. Concepto... Boletín Geológico y Minero, 128 (2): $301-328$

ANEXO II

\begin{tabular}{|c|c|c|c|c|c|c|c|}
\hline Denominación/ Topónimo & Municipio & Litotipo & Explotación & Observaciones & Activa & Coordenadas UTM & Altura \\
\hline Ca Na Pirris & Llubí & $\mathrm{P}_{1}$ & C & & No & 31 S 4992444394152 & $50 \mathrm{~m}$ \\
\hline Cala es Conills - Sant Elm & Andratx & $\mathrm{Q}$ & C & & No & 31 S 4444574380598 & $0 \mathrm{~m}$ \\
\hline Cala sa Nau & Felanitx & O & C & & No & 31 S 5213984360326 & $1 \mathrm{~m}$ \\
\hline Cala Sant Vicenç & Pollença & $\mathrm{O}$ & C & & No & 31 S 5041354418345 & $22 \mathrm{~m}$ \\
\hline Camí des Terrer Blanc & Sencelles & $P_{1}$ & C & & No & 31 S 4887874387361 & $116 \mathrm{~m}$ \\
\hline Can Banyeta & Campos & $\mathrm{PQ}$ & C & & No & 31 S 5062374359705 & $90 \mathrm{~m}$ \\
\hline Can Bon Jesús & Petra & $\mathrm{PQ}$ & C & & $\mathrm{Si}$ & 31 S 5157654389857 & $138 \mathrm{~m}$ \\
\hline Can Bordils & Manacor & $\mathrm{T}_{2}$ & C & & No & 31 S 5296174379195 & $23 \mathrm{~m}$ \\
\hline Can Peló & Manacor & $\mathrm{T}_{2}$ & C & & No & 31 S 5298084378507 & $22 \mathrm{~m}$ \\
\hline Can Romaguera & Palma & $\mathrm{PQ}$ & C & & $\mathrm{Si}$ & 31 S 4801714373087 & $37 \mathrm{~m}$ \\
\hline Can Terrola & Campos & Q & C & & No & 31 S 4978304357275 & $9 \mathrm{~m}$ \\
\hline Cas Busso & Llucmajor & $\mathrm{T}_{2}$ & C & & $\mathrm{Si}$ & 31 S 4871674360808 & $75 \mathrm{~m}$ \\
\hline Cas Corso - Can Picó & Felanitx & M & C & & $\mathrm{Si}$ & 31 S 5193614362906 & $75 \mathrm{~m}$ \\
\hline Cas Sineuers & Petra & $\mathrm{PQ}$ & C & & $\mathrm{Si}$ & 31 S 5133504386786 & $175 \mathrm{~m}$ \\
\hline Cas Villafranquer & Petra & $\mathrm{PQ}$ & C & & $\mathrm{Si}$ & 31 S 5130274385343 & $175 \mathrm{~m}$ \\
\hline Castell de Bellver & Palma & $\mathrm{T}_{1}$ & $M$ & & No & 31 S 4672094379404 & $80 \mathrm{~m}$ \\
\hline es Dos Ulls & Llucmajor & $\mathrm{P}_{2}$ & C & & No & 31 S 4882364357115 & $4 \mathrm{~m}$ \\
\hline es Gallicant & Campos & $\mathrm{PO}$ & C & & No & 31 S 5044784360385 & $51 \mathrm{~m}$ \\
\hline es Marès & Sóller & $\mathrm{Q}$ & C & & No & 31 S 4738454405841 & $2 \mathrm{~m}$ \\
\hline es Molar de Cala Pí & Llucmajor & $\mathrm{P}_{2}$ & C & Lumaquela & No & 31 S 4874084357209 & $20 \mathrm{~m}$ \\
\hline es Monjos & Porreres & $\mathrm{PO}$ & $C+M$ & & No & 31 S 5025444369130 & $130 \mathrm{~m}$ \\
\hline es Pou Salat & Llucmajor & 0 & $\mathrm{C}$ & & No & $31 \mathrm{~S} 4780814361510$ & $7 \mathrm{~m}$ \\
\hline es Ras & Felanitx & $\mathrm{O}$ & C & & No & 31 S 5218184360885 & $0 \mathrm{~m}$ \\
\hline Frontó des Molar & Manacor & $\mathrm{O}$ & C & & No & 31 S 5264084373329 & $1 \mathrm{~m}$ \\
\hline Galdent & Llucmajor & $\mathrm{PO}$ & M & & $\mathrm{Si}$ & 31 S 4900394374482 & $205 \mathrm{~m}$ \\
\hline Manresa & Alcúdia & 0 & C & & $\mathrm{Si}$ & 31 S 5111684413205 & $3 \mathrm{~m}$ \\
\hline Mayol II & Petra & $\mathrm{PQ}$ & C & & $\mathrm{Si}$ & 31 S 5135584386553 & $180 \mathrm{~m}$ \\
\hline Na Caretes & Llucmajor & $\mathrm{O}$ & C & & No & 31 S 4780684366088 & $2 \mathrm{~m}$ \\
\hline Pedreres de la Seu & Llucmajor & $\mathrm{T}_{2}$ & C & & No & 31 S 4778504363983 & $11 \mathrm{~m}$ \\
\hline Portals Vells & Calvià & $\mathrm{T}_{2}$ & $M$ & & No & 31 S 4590004369273 & $3 \mathrm{~m}$ \\
\hline
\end{tabular}


Mas Gornals, G., 2017. Hacia una tipología de la piedra de marés de Mallorca. Concepto... Boletín Geológico y Minero, 128 (2): $301-328$

\begin{tabular}{|c|c|c|c|c|c|c|c|}
\hline Denominación/ Topónimo & Municipio & Litotipo & Explotación & Observaciones & Activa & Coordenadas UTM & Altura \\
\hline s'Estret des Temps & Santanyí & $\mathrm{Q}$ & C & & No & 31 S 5154294353790 & $3 \mathrm{~m}$ \\
\hline sa Cabana & Llucmajor & PQ & C & & $\mathrm{Si}$ & 31 S 4880354375537 & $226 \mathrm{~m}$ \\
\hline sa Canova & Campos & $\mathrm{PQ}$ & C & & No & 31 S 5019984354483 & $31 \mathrm{~m}$ \\
\hline sa Cova & Llucmajor & $\mathrm{P}_{2}$ & C & Lumaquela & No & 31 S 4815124374705 & $60 \mathrm{~m}$ \\
\hline sa Fontsanta de sa Teulera & Palma & $\mathrm{T}_{1}$ & M & & No & 31 S 4672244380658 & $47 \mathrm{~m}$ \\
\hline sa Gruta & Manacor & $\mathrm{T}_{2}$ & C & & No & 31 S 5304954379759 & $13 \mathrm{~m}$ \\
\hline sa Mola & Felanitx & $\mathrm{S}$ & $C+M$ & Subtipo-a & No & 31 S 5118894368744 & $140 \mathrm{~m}$ \\
\hline sa Taleca & Escorca & Q & C & & No & 31 S 4783214408773 & $2 \mathrm{~m}$ \\
\hline saTaulada & Sta. Margalida & $\mathrm{T}_{2}$ & C & & Si & 31 S 5120154395023 & $85 \mathrm{~m}$ \\
\hline Santa Bàrbara & Manacor & $\mathrm{T}_{2}$ & C & & No & 31 S 5278864376580 & $20 \mathrm{~m}$ \\
\hline ses Cadenes & Palma & Q & C & & No & 31 S 4790994374100 & $20 \mathrm{~m}$ \\
\hline ses Coves & Sta. Eugènia & $\mathrm{P}_{1}$ & $C+M$ & & No & 31 S 4849334386437 & $160 \mathrm{~m}$ \\
\hline ses Covetes & Campos & Q & C & & No & 31 S 4972984356207 & $0 \mathrm{~m}$ \\
\hline ses Olles & Llucmajor & Q & C & & No & 31 S 4778954366751 & $8 \mathrm{~m}$ \\
\hline ses Piquetes & Santanyí & Q & C & & No & 31 S 5090244350147 & $5 \mathrm{~m}$ \\
\hline Son Morei & Muro & $\mathrm{T}_{2}$ & C & & No & 31 S 5061004399390 & $46 \mathrm{~m}$ \\
\hline Son Mulet & Llucmajor & $\mathrm{PQ}$ & $C+M$ & & No & 31 S 4955964369746 & $153 \mathrm{~m}$ \\
\hline Son Oliver & Campos & $\mathrm{P}_{2}$ & M & & No & 31 S 5053554367246 & $64 \mathrm{~m}$ \\
\hline Son Pere Andreu & Manacor & $\mathrm{S}$ & $C+M$ & Subtipo-a & No & 31 S 5156064380551 & $72 \mathrm{~m}$ \\
\hline Son Rafeló & Llucmajor & $\mathrm{T}_{2}$ & C & & Si & 31 S 4926584361580 & $51 \mathrm{~m}$ \\
\hline Son Sanç & Santanyí & M & C & & $\mathrm{Si}$ & 31 S 5125244358069 & $73 \mathrm{~m}$ \\
\hline Son Sureda Pobre & Manacor & $\mathrm{PQ}$ & C & & No & 31 S 5175254387119 & $176 \mathrm{~m}$ \\
\hline Son Toni Amer & Campos & $\mathrm{PQ}$ & C & & No & 31 S 5044024359565 & $49 \mathrm{~m}$ \\
\hline Son Vadó & Porreres & $\mathrm{M}$ & - & & No & 31 S 5051324370042 & $95 \mathrm{~m}$ \\
\hline Torremarina & Campos & $\mathrm{O}$ & C & & No & 31 S 4972514357514 & $4 \mathrm{~m}$ \\
\hline Torrenova & Calvià & $\mathrm{T}_{1}$ & C & & No & 31 S 4610134373669 & $20 \mathrm{~m}$ \\
\hline Vanrell & Petra & $\mathrm{PQ}$ & C & & $\mathrm{Si}$ & 31 S 5133884386843 & $171 \mathrm{~m}$ \\
\hline Vernissa Vell & Sta. Margalida & $\mathrm{T}_{2}$ & C & & Si & 31 S 5094604398141 & $60 \mathrm{~m}$ \\
\hline Vinromà & Muro & $\mathrm{T}_{2}$ & C & & No & 31 S 5051244400144 & $51 \mathrm{~m}$ \\
\hline
\end{tabular}


Anexo I. Valores específicos correspondientes a los diferentes litotipos y cualidades. Da: densidad aparente $\left(\mathrm{g} / \mathrm{cm}^{3}\right)$, Po: porosidad abierta (\%), P: porosidad total (\%), Ca: coeficiente de absorción (\%), Rc: resistencia a la compresión $\left(\mathrm{kg} / \mathrm{cm}^{2}\right)$, Rf: resistencia a la flexotracción $\left(\mathrm{kg} / \mathrm{cm}_{2}\right)$, Ri: resistencia al impacto $(\mathrm{cm})$, Sol: solubilidad $(\%$ residuo insoluble), Res: tipo de residuo (C: cuarzo, A: arcilla), Rcris: resistencia a la cristalización (ciclos mínimos), Cal: Calcita (\%), Cua: Cuarzo (\%), Dol: Dolomita (\%), Fuentes: 1- Moreno and Muñoz (1988), 2- Gibert (1997), 3- Amengual and Serra (2008), 4- SánchezCuenca (2010).

Annex I. Specific values for the different lithotypes and qualities. Da: bulk density $\left(\mathrm{g} / \mathrm{cm}_{3}\right)$, Po: open porosity (\%), P: total porosity (\%), Ca: absorption coefficient (\%), Rc: Compressive strength $\left(\mathrm{kg} / \mathrm{cm}^{2}\right)$, Rf: flexural tensile strength $\left(\mathrm{kg} / \mathrm{cm}^{2}\right)$, Ri: impact resistance $(\mathrm{cm})$, Sol: solubility (\% insoluble residue), Res: type of waste (C: quartz a: clay), Rcris: resistance to crystallization (minimum cycles), Cal: Calcite (\%), Cua: Quartz (\%), Dol: Dolomite (\%), Sources: 1- Moreno and Muñoz (1988), 2- Gibert (1997), 3- Amengual and Serra (2008), 4- Sánchez-Cuenca (2010).

Anexo II. Relación y geolocalización de las principales canteras de marés de Mallorca. Coordenadas UTM datumWGS 84. Explotación: C- Cantera, M- Mina. La altura indica la cota del terreno original de la cantera sobre el nivel del mar.

Annex II. Relationship and geolocation of the main mares quarries of the island of Mallorca. Coordinates UTM WGS 84 datum. Exploitation: C- Quarry, M-Mine. The height indicates the level of the original ground of the quarry above the sea.

Recibido: diciembre 2015

Revisado: febrero 2016

Aceptado: abril 2016

Publicado: junio 2017 